\title{
Reproductive parameters of the fisher (Pekania pennanti) in the southern Sierra Nevada, California
}

\author{
Rebecca E. Green, * Kathryn L. Purcell, Craig M. Thompson, Douglas A. Kelt, and Heiko U. Wittmer \\ United States Forest Service, Pacific Southwest Research Station, Sierra Nevada Research Station, 2081 E Sierra Avenue, Fresno, \\ CA 93710, USA (REG, KLP, CMT) \\ Department of Wildlife, Fish, and Conservation Biology, University of California, One Shields Avenue, Davis, CA 95616, \\ USA (DAK) \\ School of Biological Sciences, Victoria University of Wellington, P.O. Box 600, Wellington 6140, New Zealand (HUW)
}

* Correspondent: regreen@ucdavis.edu

\begin{abstract}
Quantifying reproductive parameters is essential for developing effective conservation plans for species of concern; however, studying reproduction in wild settings can be challenging and local data are frequently unavailable. The fisher (Pekania pennanti) is an elusive forest-dwelling carnivore of conservation concern that occurs across much of boreal North America and reaches the southernmost limit of its distribution in the southern Sierra Nevada (SSN) in California. Data on fisher reproduction in this region are limited and applicability of parameters from other areas is uncertain. To clarify how fisher populations in the SSN compare with those elsewhere in North America, we conducted a comprehensive review of available literature on reproduction throughout the species' range in North America. We then compared findings from the review with data we collected during 7 years in the SSN, focusing on the proportion of females reproducing, litter size, and the parturition date. On average across the fisher's range, the proportion of adult females that reproduced was 0.71 (range: $0.40-1.00 ; n=16$ studies), litter size was 2.5 (range: $1-4 ; n=16$ studies), and parturition occurred on 25 March (range: 3 March-17 April; $n=16$ studies). In our study area, we tracked 42 adult female fishers, 35 of which reproduced and used 257 reproductive dens (74 natal, 175 maternal, 8 early failures); 0.86 of our females attempted denning (range: 0.79$1.0 ; n=93$ opportunities) and 0.75 were successful (range: $0.64-1.0 ; n=91$ opportunities monitored through the den season). Mean litter size was 1.57 (range: $1-3 ; n=75$ litters) and mean parturition date was 30 March (range: 17 March-12 April; $n=69$ natal dens initiated). Female fishers at the southern limit of their distribution in the SSN reproduced at a rate comparable to or higher than elsewhere in North America, but average litter size was the lowest reported for the species. Female fishers in the SSN gave birth at similar or later dates than elsewhere in their range. We explore factors that might explain patterns of variation in fisher reproductive parameters and discuss conservation implications of our findings.
\end{abstract}

Key words: den, fisher, forest carnivore, litter size, parturition, Pekania pennanti, reproduction

Conservation of rare and declining species can be hampered by a variety of issues including habitat loss (Fahrig 1997) and over-harvest (Wittemyer et al. 2014). For rare or elusive species, another common limitation is lack of key life history information for habitat mapping, population modeling, and conservation planning (Hernández et al. 2006). Data on fundamental reproductive parameters, such as the annual proportion of females reproducing and litter size, provide insights into the status of a population and its capacity for growth (Barding and Lacki 2014). Information on local reproductive parameters can inform regional conservation plans and allow for comparisons across the species' range to better understand the flexibility of a species to respond to potential threats or extreme events such as changes in climatic conditions (e.g., drought, warmer temperatures-Hall et al. 2016; Scheele et al. 2016) or extensive habitat alteration (e.g., tree mortality, high-intensity fire-Leahy et al. 2016; Aubry-Kientz and Moran 2017).

Patterns of behavior associated with reproduction and reproductive success may be influenced by both extrinsic (e.g., climate, latitude-Bywater et al. 2010; Lada et al. 2013) and intrinsic factors (e.g., nutrition, body condition, physiologySadleir 1969). Female mammals in wild settings face many energetic challenges during reproduction that may influence whether or not an individual female gives birth at a given

Published by Oxford University Press on behalf of American Society of Mammalogists 2018.

This work is written by (a) US Government employee(s) and is in the public domain in the US. 
opportunity, her litter size, and (for some species) the number of litters per year (Oftedal and Gittleman 1989). Examples of energetic challenges may include foraging while pregnant, securing a location to give birth, lactating, and modifying behavioral patterns to raise young (Oftedal and Gittleman 1989). These challenges may be intensified for some mammalian carnivores due to large home ranges (Gittleman and Harvey 1982), energy-intensive foraging styles (Powell and Leonard 1983), lean body shapes (Brown and Lasiewski 1972), or prolonged periods of parental care (Laurenson 1995; Miller et al. 2014).

A species' reproductive timeline may be flexible in the face of variation in temperature (Gladalski et al. 2014), precipitation (Lučan et al. 2013), and food availability (Tomás 2015). Alternatively, the timeline may be relatively invariant due to physiological constraints (e.g., timing of estrus-Mead 1994) or associations with environmental factors (e.g., presence of snow cover for reproductive dens of wolverine [Gulo gulo] Aubry et al. 2007). Determining the timing of behaviors associated with reproduction can provide insights about a species' ecology, which can be used by resource managers to mitigate impacts during vulnerable activities such as parturition and rearing of young (Kanapaux and Kiker 2013; Webber et al. 2013). Many mustelid carnivores exhibit delayed implantation, in which a fertilized egg develops into a blastocyst before entering a period of suspended development (diapause); after a delay, the blastocyst implants in the uterus and development resumes (Mead 1989, 1994). In mustelids, the length of this delay ranges from 34 to 37 days in least weasels (Mustela nivalis), 259 to 276 days in American martens (Martes americana), and 327 to 358 days in fishers (Pekania pennanti-Mead 1989). Understanding and incorporating the details of a species' reproductive timeline in conservation planning efforts may facilitate successful reproduction.

The fisher is a forest-dwelling mustelid endemic to North America with unique aspects to its reproductive ecology. Among females, 1st mating can occur at 1 year of age, with parturition at 2 years (Mead 1994). Female fishers enter a brief estrus each year in early spring, and if mating is successful, implantation of the blastocyst is delayed for nearly 10 months (Mead 1994; Powell et al. 2003). Implantation is believed to be triggered by increasing day length (Pearson and Enders 1943) in association with a peak in progesterone levels in February (documented in captive female fishersCherepak and Connor 1992; Frost et al. 1997); subsequent embryonic development takes 36-42 days (Frost et al. 1997). Parturition occurs in late winter or early spring, followed about 7-10 days later by a postpartum estrus and mating (Powell et al. 2003). Females give birth and care for infant young in natal dens that are invariably in tree cavities (live trees or snags); as the kits develop, the mother often moves them to a series of 1 or more maternal dens in similarly protected locations (Powell et al. 2003).

Historically, the fisher occupied a diverse array of forest types throughout boreal North America, with southern montane extensions in the Cascade Range, Sierra Nevada, Rocky
Mountains, and eastern deciduous forests (Gibilisco 1994; Graham and Graham 1994). Unrestrained fur-trapping in the 1800 s and early 1900s led to population declines or extirpations across much of the range (Lewis and Zielinski 1996; Tapper and Reynolds 1996); long-term impacts were most pronounced where trapping coincided with or was followed by extensive timber harvest, as in the western United States (Aubry and Houston 1992; Aubry and Lewis 2003; Zielinski et al. 2005). In California, concern about the fate of fisher populations was expressed early in the 20th century by naturalists who argued that harvest rates were unsustainable (Dixon 1925; Grinnell et al. 1937; Hall 1942); these concerns led to a statewide ban on fisher trapping in 1946, which remains in effect today (Lewis and Zielinski 1996). These threats are amplified by recent issues such as habitat loss from catastrophic wildfires (Scheller et al. 2011), geographic isolation of populations (Zielinski et al. 2005), low genetic diversity (Wisely et al. 2004; Knaus et al. 2011), exposure to rodenticides (Gabriel et al. 2015), and predation by larger carnivores (Wengert et al. 2014). If fisher populations are to remain viable in the face of these issues, a comprehensive understanding of their reproductive biology is needed so that managers can strategize to support reproduction in this species.

Prior to our efforts, few reproductive dens had been found in the Sierra Nevada (Grinnell et al. 1937; Lofroth et al. 2010); consequently, local information on reproduction for guiding management activities has been lacking, yet the applicability of data from more northern regions is unknown. Fisher populations in Washington, Oregon, and California have been classified collectively as the West Coast distinct population segment (DPS), which was recently considered for listing under the Endangered Species Act (USFWS 2014). Although this listing was denied, the state of California has classified fishers in the southern Sierra Nevada (SSN) as an Evolutionarily Significant Unit that warranted "threatened" status (CDFW 2015). Extensive detection surveys in the Sierra Nevada suggest that occupancy (within areas surveyed) has remained stable over the last decade (Zielinski et al. 2013), but fishers in this region have become demographically and genetically isolated from other populations (Zielinski et al. 2005; Tucker et al. 2012). The population size in the SSN is not well known, but the number of adults may be as low as 125-250 individuals (Spencer et al. 2011), underscoring the importance of managing for reproductive success.

To describe the current state of knowledge on fisher reproduction and provide context for our field study, we conducted a comprehensive review of available literature with the objectives of characterizing 3 fundamental reproductive parameters: 1) the proportion of females reproducing, 2) litter size, and 3) the parturition date. We also collected baseline data on these parameters from wild fishers in the SSN. Based on previous findings (Lofroth et al. 2010), we hypothesized that fisher reproductive parameters would display 2 basic geographic patterns: a latitudinal gradient and regional clustering within the West Coast DPS relative to the broader range. We predicted that reproductive output (proportion of females reproducing and litter size) 
would decrease from north to south (e.g., Lord 1960; Keith et al. 1966). We also predicted that the longer day length in the south would lead to earlier implantation of blastocysts (Mead 1994), resulting in a pattern of parturition dates that were earlier in the south to later in the north. Because fishers within the West Coast DPS are likely influenced by similar regional factors (e.g., habitat, body size, genetics) compared to other areas (Lofroth et al. 2010), we expected reproductive output in the SSN would be comparable to the West Coast DPS. We expected the proportion of females reproducing and litter size in the West Coast DPS would be lower than in other parts of the range, however, due to factors likely to influence female body condition (e.g., smaller prey biomass in the southern portion of the fisher's range-Zielinski et al. 1999; Fuller and Sievert 2001). Last, we investigated whether reproductive parameters of fishers across their range correlated with climatic variables (temperature, precipitation), as was documented for litter size with a broader array of carnivores (Tökölyi et al. 2014). We consider our findings on fisher reproductive parameters in the SSN relative to other geographic areas and discuss how these data might inform conservation and management plans for this species.

\section{Materials And Methods}

Study area.-We conducted field work from June 2007 through June 2014. Our study area encompassed roughly 43,500 ha of the Sierra National Forest southeast of Shaver Lake, California, United States $\left(37^{\circ} 3^{\prime} \mathrm{N}, 119^{\circ} 11^{\prime} \mathrm{W}\right)$, on the west slope of the SSN, with Yosemite National Park to the north and Kings Canyon National Park to the south (Fig. 1). We focused our research activities within an elevation band ranging from 915 to $2,385 \mathrm{~m}$ a.s.l., where fishers are known to occur (Purcell et al. 2009). Because our study was located primarily within the Kings River watershed, we refer to our study as the Kings River Fisher Project (KRFP). Most precipitation occurred as rain in the fall and snow in the winter at elevations $\geq 1,500 \mathrm{~m}$; precipitation levels were normal during most of the study, but conditions were hotter and drier beginning in 2012 through 2014 (Mann and Gleick 2015).

Dominant tree species in the study area included California black oak (Quercus kelloggii), canyon live oak (Q. chrysolepis), incense cedar (Calocedrus decurrens), ponderosa pine (Pinus ponderosa), sugar pine ( $P$. lambertiana), and white fir (Abies concolor). Vegetation within the study area was dominated by lower montane vegetation types, including ponderosa pine-mixed conifer forest, white fir-mixed conifer forest, giant sequoia (Sequoiadendron giganteum)-mixed conifer forest (Fites-Kaufman et al. 2007), and montane hardwood forest (Allen-Diaz et al. 2007). Patches of deciduous forest, meadows, rock outcrops, and montane chaparral (Fites-Kaufman et al. 2007) occurred at middle to high elevations within our study area, with mixed chaparral at lower elevations (Keeley and Davis 2007). The USDA Forest Service is the primary land manager, but some land was privately owned. During the last century, management activities on this landscape have included timber harvest, prescribed fire, and residential development, but areas of mature forest and patches of large remnant trees are still present. Fire suppression has led to increases in shadetolerant tree species and fuels (Fites-Kaufman et al. 2007).

Literature review.-To compile data on fisher reproductive parameters throughout the species' range, we 1) searched digital databases, 2) examined citations in publications on fisher

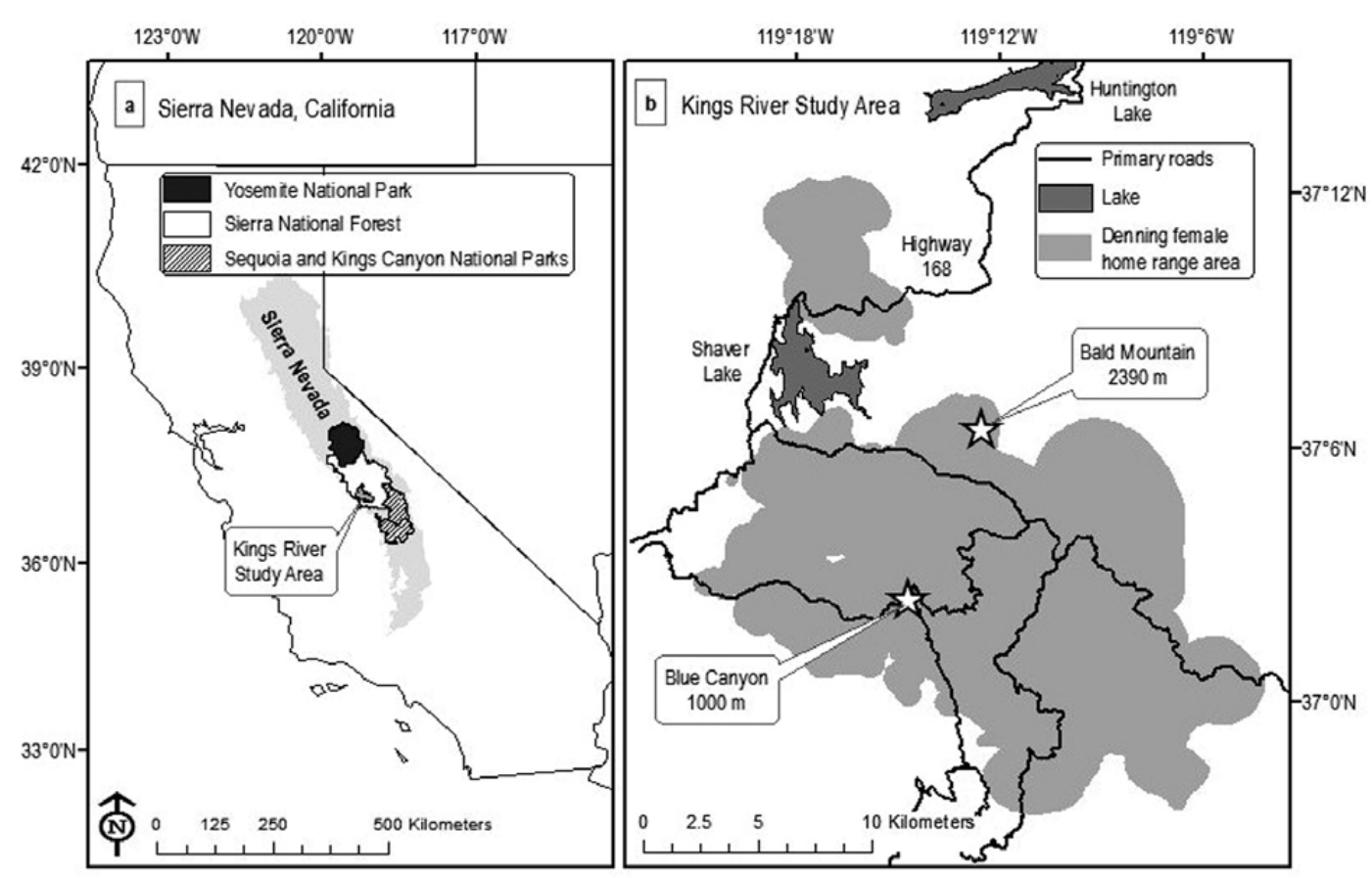

Fig. 1. - Location of the Kings River Fisher (Pekania pennanti) Project study area relative to (a) the Sierra National Forest and adjacent National Parks in the Sierra Nevada, and (b) local landmarks near Shaver Lake, California. The light gray shading in (b) denotes a 1-km buffer around trap locations (2007-2014) and the primary area of fisher monitoring. 
ecology and reproduction, and 3) contacted fisher researchers personally. Database searches were conducted in Wildlife and Ecology Studies Worldwide and BIOSIS Previews using the terms "den," "fisher," "Martes pennanti," "Pekania pennanti," and "reproduction." If a project was referenced in multiple sources, we included data from only the most relevant reference in a summary.

We examined all citations found during our search, but focused on sources with clear data on the parameters of interest. In addition, only sources with sample sizes $\geq 2$ individual fishers or observations for $\geq 2$ reproductive seasons for an individual female were included in summaries. The proportion of females reproducing was measured by monitoring dens in the wild (e.g., Matthews et al. 2013a; Sweitzer et al. 2015), observing females in captivity (e.g., Frost and Krohn 1997), studying reproductive tracts obtained from carcasses (e.g., Crowley et al. 1990), and assessing the condition of teats in live animals (e.g., Matthews et al. 2013b). Litter sizes were counted using dencavity investigations, remote cameras, observations at research facilities and fur farms, and examination of reproductive tracts for corpora lutea, blastocysts, embryos, or placental scars. Parturition dates were documented in both captive and wild settings. Because methods and terminology varied among studies, we developed standardized terminology on fisher reproduction to facilitate interpretation and improve future studies (Table 1).

In some cases, parameter values were not reported by year, making assessment of annual variation impossible or uninformative; consequently, mean values for parameters were generally pooled across years within a source, or reported as they were presented in the original publications. Because our primary goal was to investigate geographic variation in reproductive parameters, we included all sources available (that met the criteria above) to assess variation across the range and to highlight geographic areas where further data are needed. To generate comparable values for the proportion of females reproducing, we identified the number of den attempts relative to den opportunities during a study; we calculated den successes as the proportion of opportunities in which at least $1 \mathrm{kit}$ in a litter survived through the den season (Table 1). Mean litter size was calculated based on the highest number of kits counted (to best reflect number produced) relative to the number of litters documented during the study. Mean (or in some cases only median) parturition dates were typically reported in the original publication, but occasionally these were generated directly from source data.

We used 2-way $t$-tests to compare mean litter sizes and parturition dates in captive versus wild settings. We used linear regression to investigate associations between latitude and each reproductive parameter in western North America (West Coast DPS combined with British Columbia); where needed, proportional data were transformed using an arcsine square root transformation prior to analyses. We also tested for a curvilinear relationship between parturition date and latitude using a quadratic equation, with sites weighted by sample size. We used a 2-way $t$-test to compare litter sizes from the West Coast DPS with the rest of the fisher's distribution.

Table 1.-Proposal for standardizing the terminology used in studies of fisher reproduction. Terms and descriptions are based on research on the Martes Complex and the authors' experience in studying fisher reproduction in the wild in western North America.

\begin{tabular}{|c|c|}
\hline Term & Description \\
\hline Reproductive female & $\begin{array}{l}\text { A female that shows signs of reproduction, demonstrated by use of a reproductive den, by anatomical changes (e.g., teat } \\
\text { measurements), or by observing or photographing her in the presence of kits. }\end{array}$ \\
\hline $\begin{array}{l}\text { Proportion of females } \\
\text { reproducing }\end{array}$ & $\begin{array}{l}\text { The number of adult females ( } \geq 2 \text { years) showing signs of reproduction during a defined time period divided by the number of } \\
\text { adult females monitored or assessed. To facilitate comparisons, the time frame (e.g., years), method (e.g., den location), phase of } \\
\text { reproduction (e.g., ovulation, denning), setting (e.g., wild, captive), and age class (juvenile, subadult, adult) of females should be } \\
\text { specified. }\end{array}$ \\
\hline Den opportunity & $\begin{array}{l}\text { Each spring denning season during which an individual female is an adult ( } \geq 2 \text { years) and monitored sufficiently to assess her } \\
\text { reproductive status (e.g., Powell 1993; Matthews et al. 2013a). Opportunities can be tallied for multiple animals or years for } \\
\text { comparisons among studies, but patterns of variation may be obscured. The number of individuals should be noted. }\end{array}$ \\
\hline Den attempt & $\begin{array}{l}\text { A den attempt is a den opportunity during which a female exhibits signs of parturition by localizing to a single structure on } \geq 2 \\
\text { sequential days or multiple days in a week during early spring. }\end{array}$ \\
\hline Den success & A den success is an opportunity during which a female produces and rears $\geq 1$ kit for the entire den season. \\
\hline $\begin{array}{l}\text { Den failure (early, late, or due } \\
\text { to mortality) }\end{array}$ & $\begin{array}{l}\text { Den failures occur when females stop attending dens where kits are presumed or known to be. Early failures are cases where } \\
\text { females localize to } 1 \text { structure near the time of parturition (i.e., den attempt), then stop attendance; presence of kits may not be } \\
\text { verified, leaving ambiguity about whether parturition occurred. Late failures occur when females stop den visitation after } \sim 3 \\
\text { weeks of attendance. Failures from mortality occur when females die during the den season. }\end{array}$ \\
\hline Reproductive den & $\begin{array}{l}\text { A reproductive den is the refuge used by a reproductive female to conceal herself and her kits while they are young, vulnerable, } \\
\text { and nursing in spring and early summer. Typical den structures are live trees or snags with cavity microsites. A natal den is where } \\
\text { parturition occurs; sites used subsequent to the natal den are maternal dens. }\end{array}$ \\
\hline Litter size & $\begin{array}{l}\text { The number of kits known to be produced by an individual female in a given year. In a parallel to literature on litter sex ratios, we } \\
\text { note that litter sizes may be primary (generally measured as number of embryos in utero), secondary (the number born), or ter- } \\
\text { tiary (the number at independence from the mother). Comparisons can be improved by noting the time frame and methods used } \\
\text { for counts; here, we used the largest (usually earliest) count to represent the number born. }\end{array}$ \\
\hline Parturition date & $\begin{array}{l}\text { The date when an adult female gives birth. In field studies, parturition is assumed to occur when a female first localizes to a natal } \\
\text { den; the date is estimated based on den attendance behavior, not direct observation. In captivity, females typically retreat into nest } \\
\text { boxes. }\end{array}$ \\
\hline Den season & $\begin{array}{l}\text { The den season begins when females localize to a natal den structure and give birth. The den season ends as females discontinue } \\
\text { localization at individual structures for extended periods. }\end{array}$ \\
\hline
\end{tabular}


Latitude can serve as a proxy for various climatic variables, but the nature of the relationship may vary throughout the range of the fisher. Following Tökölyi et al. (2014), we reduced a set of climatic variables using principal components analysis (PCA) for comparison with the 3 reproductive parameters of interest. We selected bioclimatic variables that may be relevant to litter size in carnivores (Tökölyi et al. 2014), and obtained geographically referenced raster data (10-min spatial scale) from WorldClim (Hijmans et al. 2005; www.worldclim.org). Because descriptions of variables differed slightly between these 2 sources, we used the terms presented in Tökölyi et al. (2014) and note the associated WorldClim bioclimatic variable used in our analysis. Climatic variables included mean annual temperature (Bio1), temperature variability (mean of monthly $S D$ s; Bio4), temperature seasonality (difference between yearly maximum and minimum; Bio7), and mean annual precipitation (Bio12 divided by 12). We overlaid reproductive parameters in ordination space, and assessed relationships among reproductive parameters with informative PCA axes using linear regression; the number of informative axes was determined both visually (Scree plot) and with a Monte Carlo randomization (see McCune et al. 2002). We ran separate PCAs for each parameter of interest, because the number of sites with data for these reproductive parameters differed.

Trapping and handling procedures on the KRFP.-We trapped fishers primarily during the fall and winter and avoided trapping from March to June to preclude catching late-term or lactating females (Green et al. 2017). In the early years of the project, we trapped during the summer, but success was low, due partly to the activities of black bears (Ursus americanus); moreover, juveniles caught before October were too small for the radiocollars we used. We captured fishers using live traps (model 108; Tomahawk Live Trap, Hazelhurst, Wisconsin) affixed with wooden cubby boxes as shelter (Seglund 1995). We baited traps with a chicken leg in a sock hung from the roof of the wire cage near the cubby; bait lure was dabbed on the sock and long-distance lure applied to a nearby tree trunk. In cold weather, we placed fleece inside the cubby for insulation and positioned corrugated black plastic (Coroplast, Vanceburg, Kentucky) over the trap to keep the interior dry. Traps were checked each morning, bait was added if eaten or replenished to avoid desiccation at 7-day intervals and the long-distance lure was refreshed every 3 days.

Animals were sedated with Ketamine $(22.5 \mathrm{mg} / \mathrm{kg}) \mathrm{mixed}$ with Diazepam or Midazolam $(0.125 \mathrm{mg} / \mathrm{kg}$ ) for processing (see Green 2017 for further details). Fishers $\geq 1.7 \mathrm{~kg}$ were fitted with Holohil radiocollars (model MI-2M, 31 g; Holohil Systems Ltd, Carp, Ontario, Canada) with a handmade breakaway (Thompson et al. 2012). We used Advanced Telemetry Systems (ATS) collars (model 1920, 38 g; ATS, Inc., Isanti, Minnesota) on some animals in the 1 st year of the study. Holohil collars weighed $<2 \%$ of body weight while ATS collars were $<3 \%$. Animals were marked with pit tags (passive integrated transponders; Biomark, Boise, Idaho) inserted subcutaneously between the shoulder blades.
Fishers were classified into 3 age groups (assuming a birth date of 1 April). Juveniles (< 1 year) had very sharp molar cusps, no sagittal crest, and teats of females showed no sign of prior reproduction (nulliparous). Subadults ( $\geq 1$ and $<2$ years) showed a slight rounding of molar cusps, a partially developed sagittal crest (evident in males, none or subtle in females), and the teats of females indicated they were nulliparous (i.e., had never bred). Adults ( $\geq 2$ years) had molar cusps with increased rounding or flattening, a well-defined sagittal crest (pronounced in males, delicate in females), and the teats of females often indicated they were parous (i.e., had bred previously). Permits were obtained from the California Department of Fish and Wildlife, techniques were approved by the Institutional Animal Care and Use Committee at the University of California, Davis, and methods met guidelines approved by the American Society of Mammalogists for the use of wild mammals in research (Sikes et al. 2016).

KRFP: den location and monitoring.-We monitored fishers year-round using ground telemetry, but occasionally used aerial telemetry collaboratively with other fisher researchers (see Sweitzer et al. 2015). Starting in March, we monitored the movements of adult females closely each day (particularly in the morning hours) to determine when they localized to a particular area or structure, indicating that parturition had occurred (Green et al. 2017). We used a combination of triangulation and homing techniques (Millspaugh and Marzluff 2001; Zielinski et al. 2004) to identify resting locations. A resting structure located between early March and late June was considered a den if a female used it for $\geq 2$ consecutive days, on multiple occasions over a week, or if kits were documented (observed or photographed). Once a den was located, we monitored use of the structure from a distance using a yagi antenna for several subsequent days. Then we discreetly homed to the site on foot every 4-5 days to confirm that the female was using the same structure.

We determined litter size each year (2008-2014) by investigating den cavities and using remote cameras. If a den tree was safe for climbers, we waited until kits were $\geq 3$ weeks old, then ascended the tree to examine the cavity while the female was away from the den (Matthews et al. 2013a; Green et al. 2017). We occasionally observed kits directly inside the cavity, but most often we lowered a miniature security camera connected to a video camera with a monitor into the chamber to count young and record video. If the den cavity was relatively low, we sometimes used a camera mounted on a telescoping pole to examine the chamber. While investigating cavities, we monitored the activity of the female via telemetry; if we determined she was returning to her den, we terminated efforts and left the area. In other cases, we positioned 1-3 remote cameras (models PC800, PC85, and PM35T25; Reconyx, Holmen, Wisconsin) facing the den tree bole to photograph females moving kits to new dens. Remote cameras provided information on behavior, but sometimes missed females moving kits due to slow trigger speed, disturbance (e.g., by black bears), or females using routes out of the camera's view. We tried to balance the acquisition of data with the potential for disturbance, and monitored dens after count efforts to ensure that kits were not abandoned. If a count effort was unsuccessful or we suspected a female 
moved dens due to research activity, we typically waited $\geq 1$ week before another attempt.

We investigated the relationship between female weight at capture (an indication of body condition) and denning status (yes or no) at the next denning opportunity using a generalized linear mixed model with a logit function fit by maximum likelihood (Laplace approximation) using each female as a random effect. We included only occasions where females would be $\geq$ 2 years old by the next den opportunity and for which we subsequently knew den status; in the few cases where females were caught twice between den seasons, we used the weight from the latter capture. We conducted statistical analyses using Stata 12.1 (StataCorp 2011), R version 3.2.2 (R Core Development Team 2015), and PC-ORD (McCune and Mefford 2011).

\section{Results}

Our literature review yielded 54 sources with information on fisher reproduction, of which 36 contained primary data that we included in $\geq 1$ summary (Supplementary Data SD1). Sample sizes for adult females varied from 1 to 42 for den-monitoring studies, 1 to 26 for captive settings, 5 to 94 for projects that assessed teat condition, and 3 to 1,173 for examinations of reproductive tracts (including fishers trapped for fur). Many sources yielded data on some, but not all, parameters of interest (Table 2). Because sources of information were not equally distributed across the range (see Fig. 3), some investigations of latitudinal gradients were restricted to the west coast of North America where comparable data were available from north to south.

Literature review: proportion of females reproducing.-The mean proportion of females reproducing ranged from 0.40 to 1.00 among sources using different methods in wild and captive settings (Table 3 ). Results varied by methodology; the estimated mean proportion of females reproducing based on active or recent lactation at captures $(0.52 ;$ R. Truex, U.S. Forest Service, pers. comm.) and on the presence of placental scars in carcasses (0.58—Crowley et al. 1990) were moderate compared

Table 2.-Sources with data on reproductive parameters across the range of fishers (Pekania pennanti) in North America. Only sources in which individual females were monitored during parturition were included. ID denotes site locations indicated in Fig. 3. Mean parturition dates were available for most, but not all, studies; sources reporting only median values are denoted with an asterisk.

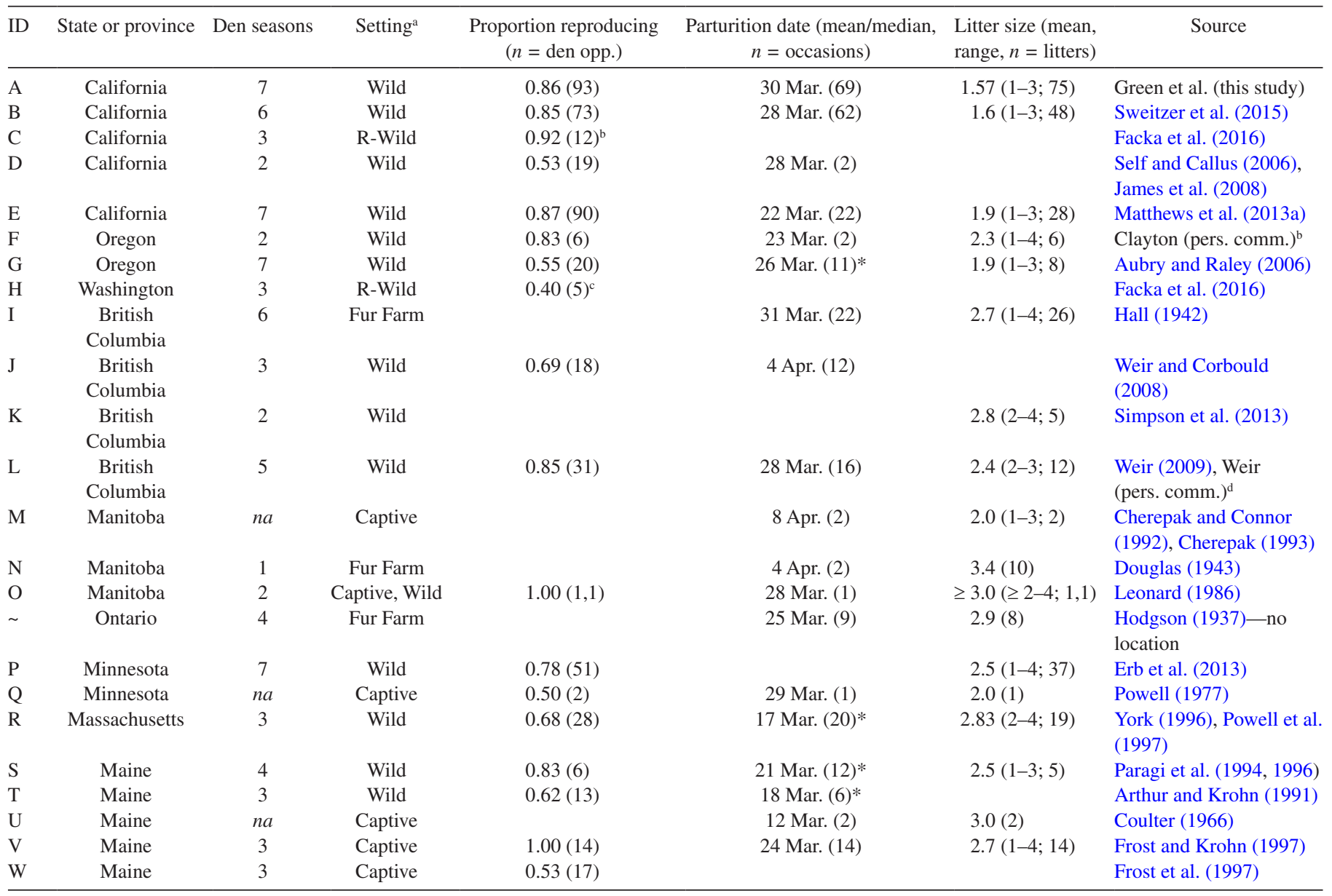

${ }^{a}$ Captive (wild or captive born females in outdoor pens for research), Fur Farm (wild or captive born females in outdoor pens for fur production), Wild (wild caught females monitored in wild setting), R-Wild (wild caught females that were part of a recent translocation and monitored in a wild setting).

b (D. Clayton, USDA Forest Service, pers. comm.).

c Only values for females released early during translocation are noted and used in summaries; values for females released late were 0.38 (CA) and 0.11

(WA-Facka et al. 2016).

d (R. D. Weir, British Columbia Ministry of Environment, pers. comm.) Downloaded from https://academic.oup.com/jmammal/advance-article-abstract/doi/10.1093/jmammal/gyy040/4980718 
Table 3.-Literature review of 3 key reproductive parameters for fishers (Pekania pennanti) in North America paired with our findings from the Kings River Fisher Project (KRFP) in the southern Sierra Nevada, California.

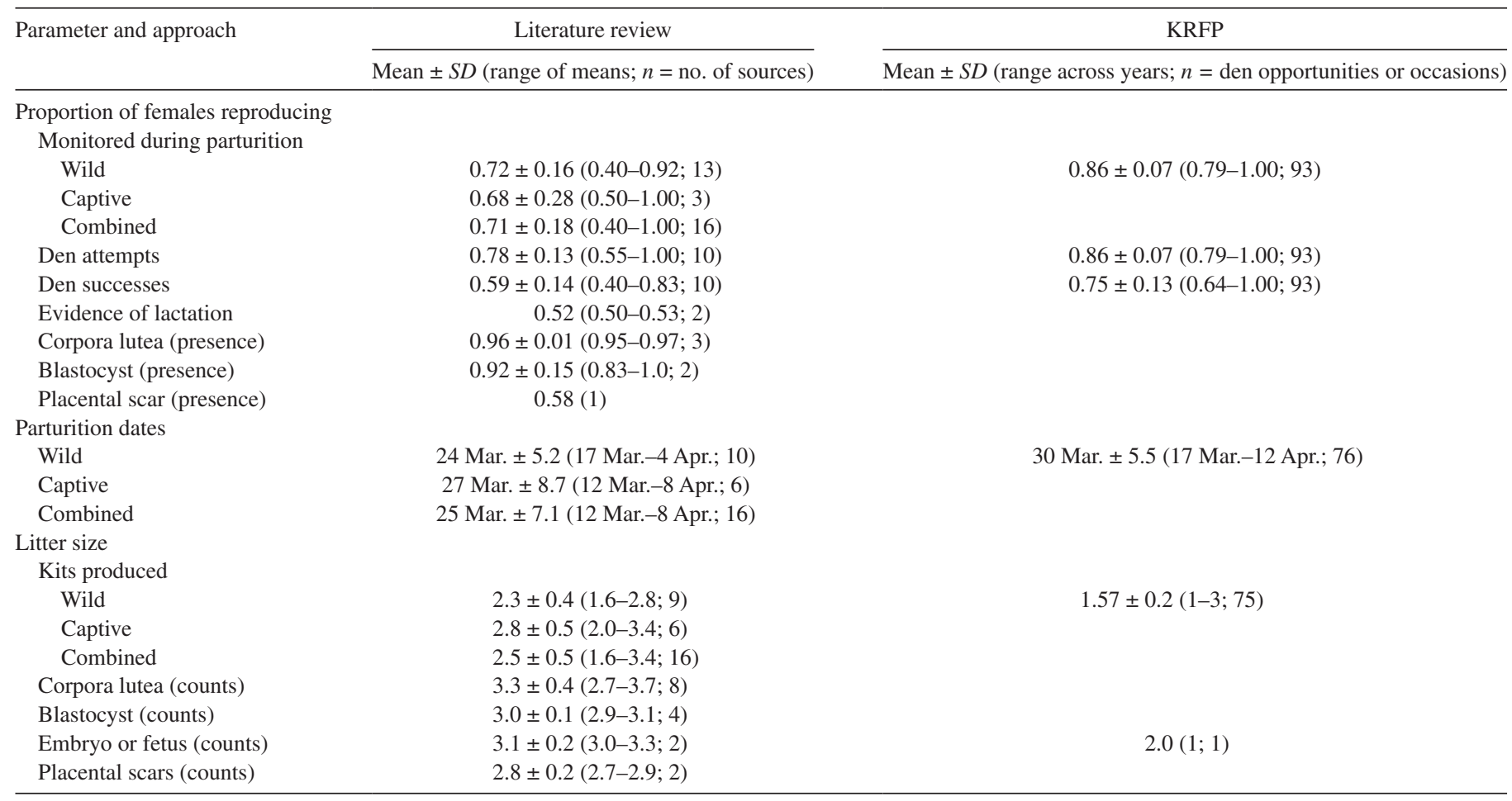

to sources using the presence of blastocysts $(0.92$ - Hamilton and Cook 1955; Crowley et al. 1990) or corpora lutea (0.96Shea et al. 1985; Douglas and Strickland 1987; Crowley et al. 1990; Table 3). In studies that monitored individual females during parturition (captive and wild settings), the mean proportion of females reproducing was $0.71(n=16$; Tables 2 and 3$)$. Not all attempts were successful; among 11 studies (including KRFP) where females were monitored in the wild, the mean proportion that attempted to den $(79 \%)$ was $15 \%$ higher than the proportion that successfully reared $\geq 1$ kit (64\%; Fig. 2). In sources where females were monitored during parturition on the west coast, we did not find a relationship between the proportion of females reproducing and latitude $\left(R^{2}=0.03\right.$, $\left.F_{1,9}=0.32, P=0.59 ; n=11\right)$. Using data from across North America, the proportion of females reproducing was not associated with the dominant axes of a PCA based on bioclimatic variables $\left(R^{2}=0.06, F_{1,13}=0.79, P=0.39\right)$; this PCA yielded 1 informative axis $(\lambda=2.89)$ that explained $72 \%$ of the variance (Supplementary Data SD2).

Literature review: litter size.-Mean litter size declined with developmental stage, being greatest when using counts of corpora lutea (3.3), and declining through counts of blastocysts (3.0), embryos or fetuses (2.8; including KRFP), placental scars (2.8), and live kits post-parturition (2.5; Table 3). Moreover, mean litter size in captivity (2.9) was greater than in wild settings $\left(2.3 ; t_{13}=2.17, P<0.05\right)$. Females in the West Coast DPS (including KRFP) had smaller litters than the rest of the range $\left(\bar{X}=1.9\right.$ and 2.4 , respectively; $t_{14}=-4.56, P<0.01$; Table 2; Fig. 3). Among 8 sites on the west coast, litter size was positively correlated with latitude $\left(R^{2}=0.81, F_{1,6}=2.09, P<\right.$
0.01). Using available data from across North America, mean litter size was significantly associated with the dominant axis of a PCA based on climate variables $\left(R^{2}=0.61, F_{1,11}=17.18, P\right.$ $<0.01$; Fig. 4; Supplementary Data SD2). This PCA yielded 1 informative axis $(\lambda=3.27)$ that explained $82 \%$ of the variance. Positive values on this axis represented sites with warmer mean annual temperatures and higher mean annual precipitation; these sites tended to have smaller litters. Negative values on the axis reflected sites with greater seasonality and variability of temperature; these sites tended to have larger litters.

Literature review: parturition date.-Where dates associated with natal den initiation (wild settings) or parturition (captive settings) were recorded, the mean parturition date (25 March, $n=16$; Table 3; Fig. 5) was similar for wild and captive fishers (24 and 27 March, respectively; $t_{14}=-0.82, P=0.42$; Table 3). The range of mean parturition dates was relatively narrow among sources (12 March-8 April), with a total range from 3 March to 17 April. Based on data from 9 studies on the west coast, latitude did not show a strong relationship with mean date of parturition $\left(R^{2}=0.27, F_{1,7}=2.55, P=0.15\right)$. However, using data from all sites and a quadratic equation, we found a curvilinear relationship between mean (or median) parturition date and latitude $\left(R^{2}=0.60, F_{8}=6.05, P=0.03, n=11\right.$; Fig. 5). Mean date of parturition at sites across North America was not associated with dominant axes of a PCA based on bioclimatic variables $\left(R^{2}=0.06, F_{1,9}=0.61, P=0.46\right)$; this PCA yielded 1 informative axis $(\lambda=3.11)$ that explained $78 \%$ of the variance (Supplementary Data SD2).

KRFP: reproductive dens.-Between June 2007 and June 2014, we trapped 121 fishers on 260 occasions, including 155 


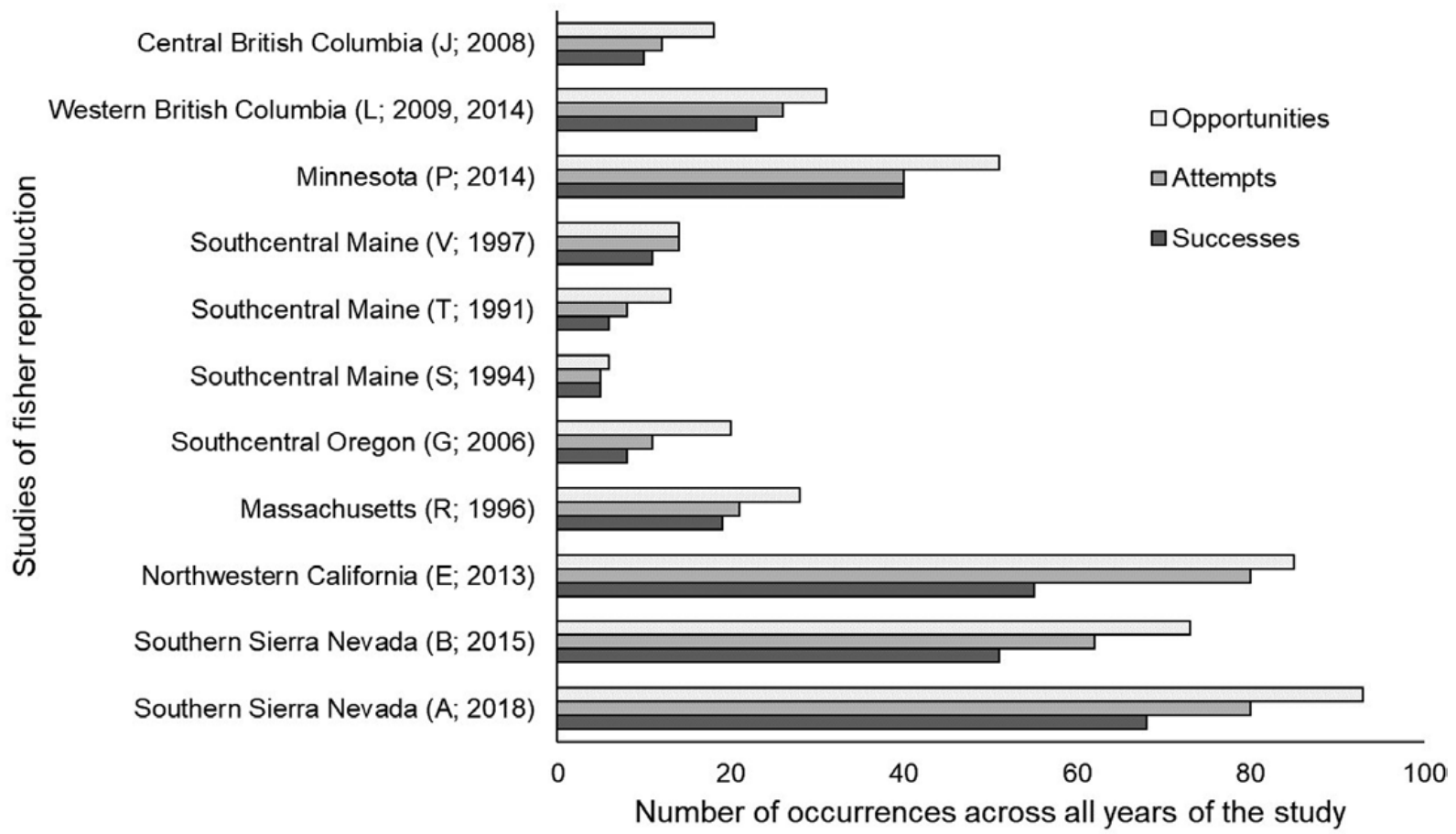

Fig. 2.- Relationship between the number of den opportunities, attempts, and successes in 11 studies where adult female fishers (Pekania pennanti) were monitored during parturition and through the den season in wild settings across North America. Study sites are arranged from north (top) to south (bottom), with year of study listed for reference. Actual values were used instead of proportions to indicate differences in effort over time and by geographic area. Many early studies of fisher reproduction were conducted on the east coast, while recent longer-term studies have predominantly been in the western portion of the range.

captures of 70 females and 105 captures of 51 males (range, 1-8 captures per fisher). We placed radiocollars on 68 females and monitored them year-round. From March 2008 to June 2014, we located and monitored 257 reproductive dens $(74$ natal, 175 maternal, 8 that failed early) in 237 unique structures used by 35 adult females during 7 denning seasons. Twenty of these structures (8.4\%) were reused by the same female or by different females in different years. All structures used as reproductive dens were standing trees (live and dead) with cavities, except for 2 late maternal dens in hollow logs (see Green 2017 for details). During 68 successful denning opportunities that were monitored for the entire den season, females used an average of $3.5 \pm 1.2$ dens per year (range: 1-7). Three females remained at natal dens for an entire den season, and 3 others reused their natal den structure as a maternal den later in the same season. In 7 of the 8 early den failures, females localized to a structure for a few days, after which they were not found at the site; the exception was a female that revisited 1 tree repeatedly over a 3 -week period. We were unable to confirm kits at these early failed dens, but the behavior of females was similar to that of known denning females and in 3 cases the structures were used successfully as dens by the same female in another year. We documented 3 additional den failures due to mortality when females were killed by predators while away from their dens.

KRFP: reproductive parameters.-We monitored 42 adult females in $\geq 1$ denning season, and confirmed 35 of these at reproductive dens in $\geq 1$ year. Over 7 den seasons, we documented 93 den opportunities, 80 den attempts (86\%), and 68 den successes $(75 \%$, excluding 2 attempts of unknown fate; Table 4). The mean proportion of females attempting to den in KRFP across all years $(0.86 ; 95 \% C I=0.79-0.93)$ was higher than the mean from our literature review (0.71; Table 3$)$ and greater than $77 \%$ of other studies in Table 2.

Mean litter size for KRFP $(1.57,95 \% C I=1.44-1.71$; range: $1-3, n=75$ litters) was lower than the range-wide mean obtained in the review (2.50) and less than all other studies reviewed in Table 2. Moreover, litters of 3 were recorded only 3 times for 2 females.

Over 7 years, females initiated 69 natal dens between 17 March and 12 April (our estimated date of parturition). Excluding 5 cases where limited access (heavy snow, remote location) delayed discovery of natal dens ( $\geq 5$ days), the mean date of parturition (30 March \pm 5.5 days; $95 \% C I=29$ March-1 April) was 5 days later than the range-wide mean of 25 March. In addition, the mean date of parturition for KRFP was later than $78 \%$ of other studies in Table 2, although the range of dates from this study and other sources showed considerable overlap (Table 3). Initiation dates for assumed failed dens did not differ from those of successful dens $\left(t_{75}=-0.29, P=0.77\right)$. Females moved kits from natal to maternal dens between 4 April and 24 June $(\bar{X}=27$ April). During the first 6 years of the study (2008 through 2013), our earliest parturition date was 23 March; the spring of 2014 was unusually warm, and we recorded our earliest dates for natal den initiation in this year, 1 by a previously reproductive female (17 March) and 1 by a 1st-time breeder (19 March). 


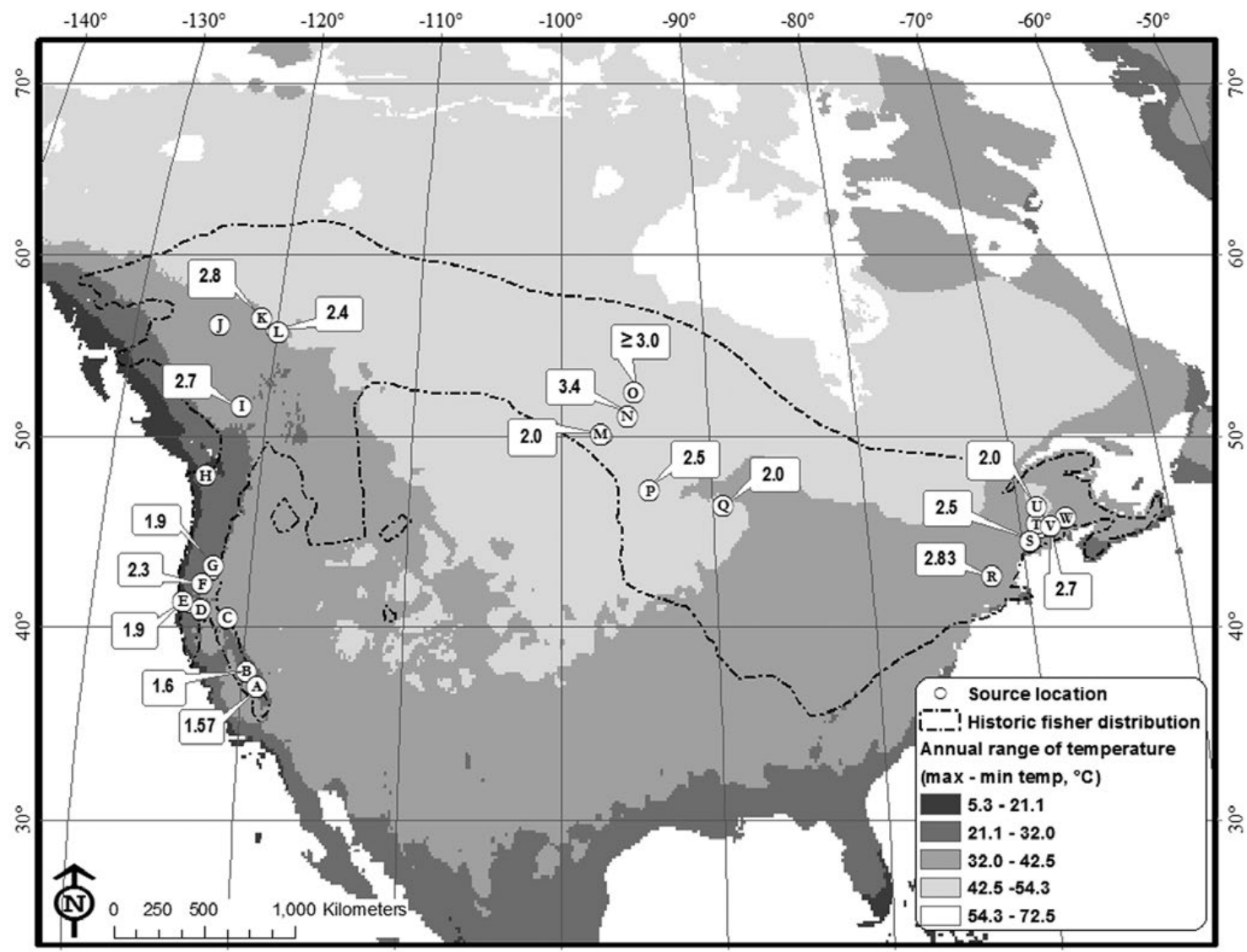

Fig. 3. - Distribution of mean litter sizes from studies of fishers (Pekania pennanti) in the wild in North America where females were monitored during parturition. Lettered sites indicate locations where data were collected on $\geq 1$ reproductive parameter (see Table 2 for references). The dashed black line denotes the historical range of the fisher based on Lewis et al. (2012). Gray shading shows annual range of temperatures (maximum-minimum) from WorldClim spatial data (Hijmans et al. 2005).

KRFP: female weight and reproduction.-Mean weights for females among years were $2.17 \pm 0.19 \mathrm{~kg}$ for adults ( $n=85$ captures, 38 females), $2.05 \pm 0.20 \mathrm{~kg}$ for subadults ( $n=39$ captures, 39 females), and $2.02 \pm 0.17 \mathrm{~kg}$ for juveniles $(n=37$ captures, 37 females). Females that denned successfully at the next opportunity after a capture were heavier $(\bar{X}=2.16 \pm 0.19 \mathrm{~kg}, n=69$ captures, 33 females $)$ than those that did not $(\bar{X}=1.99 \pm 0.16 \mathrm{~kg}, n=13$ captures, 13 females; GLM, $z_{80}=2.00, P<0.05$; Supplementary Data SD3). Females with dens that failed early did not differ in weight compared to females with successful attempts (reported above), although sample sizes were small for failed attempts $\left(\bar{X}=2.26 \pm 0.15 \mathrm{~kg}, n=7\right.$ captures of 7 females; $t_{74}=-1.33$, $P=0.19)$.

\section{Discussion}

Although studies of fisher reproductive ecology have been unevenly distributed (Fig. 3), we were still able to investigate patterns in fisher reproductive parameters associated with latitudinal gradients, regions (West Coast DPS), and climatic variables identified by Tökölyi et al. (2014). Litter size was positively correlated with latitude in western North America, although a similar pattern was not evident for the proportion of females reproducing. Reproductive output values from studies within the West Coast DPS were largely similar, although litter size in the SSN was noticeably small. Parturition dates were not earliest at more southerly sites; instead, earliest parturition dates were associated with middle latitudes while later dates tended to occur to the north and south. We also found larger litter sizes generally in areas with greater seasonality and more variable temperatures, and smaller litters at sites with warmer annual temperatures and more precipitation, as predicted by Tökölyi et al. (2014).

Proportion of females reproducing.-Some techniques used to assess reproductive performance in female fishers reflect potential rather than confirmed reproduction. Because some ova will not be fertilized and not all blastocysts will result in kits, counts of corpora lutea or blastocysts can yield inflated estimates of reproduction (Crowley et al. 1990). From a conservation perspective, the most meaningful measure of reproduction among fishers in wild settings is the proportion of females producing viable kits, which is best obtained by monitoring dens. Based on studies in our review where fishers were monitored during parturition, the overall mean proportion of adult females showing signs of reproduction in the wild was moderately high $(72 \%)$, but a much lower proportion was successful (59\%). Contrary to our prediction that fewer females 

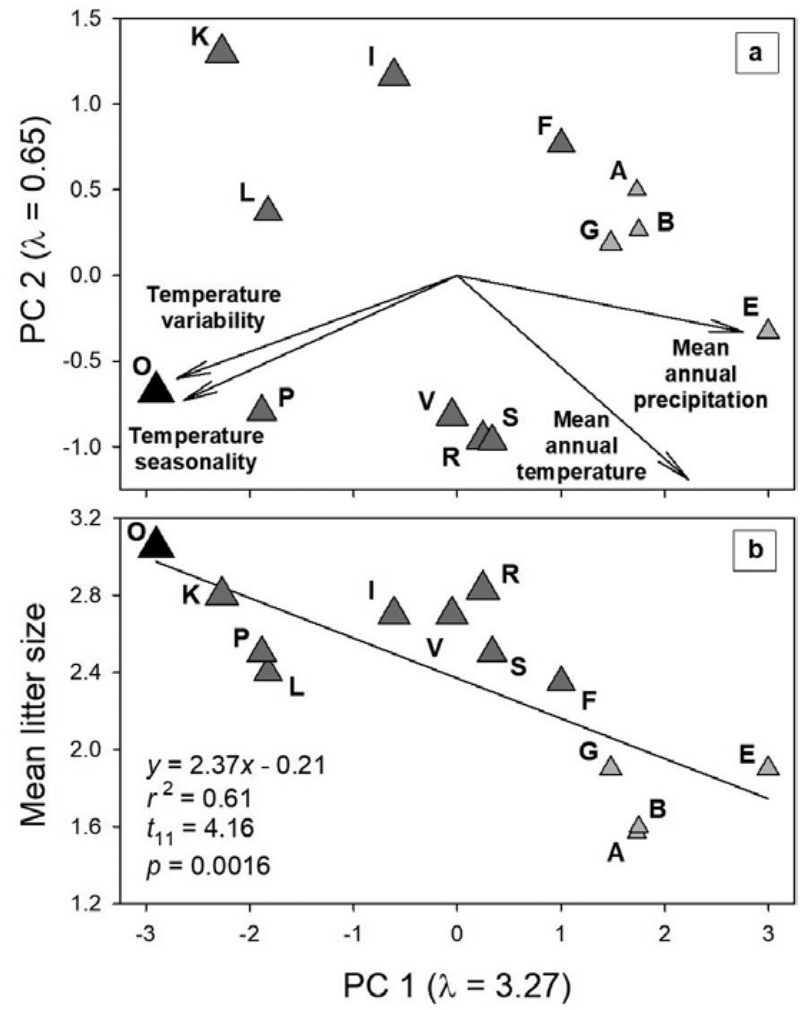

Fig. 4.- Results of principal components analysis showing the relationship between 4 bioclimatic variables and mean litter sizes for the fisher (Pekania pennanti) across North America. (a) Ordination plot showing the distribution of 13 sites in bivariate space. Symbol size and symbol color reflect mean litter size (small, gray $=<2$ kits/litter; medium, dark gray $=2-3 \mathrm{kits} /$ litter; large, black $=>3 \mathrm{kits} / \mathrm{lit}-$ ter). Vectors indicate the distribution of selected bioclimatic variables. Only the 1st axis was informative, and reflects a gradient from sites with greater seasonality and variability of temperature to those with warmer mean annual temperatures and higher mean annual precipitation. (b) Regression of mean litter size on PC 1, showing a significant negative association between these parameters. Sites with larger litters exhibited greater seasonality and more variable temperatures, whereas sites with smaller litters were characterized by warmer annual temperatures and more precipitation.

would reproduce at more southern latitudes, the proportion of females attempting to reproduce (86\%) and the proportion that did so successfully $(75 \%)$ in the SSN exceeded these rangewide mean values. Regionally, our results were largely comparable to those from other studies in the West Coast DPS (e.g., Matthews et al. 2013a, 87\% and 65\%, respectively; Sweitzer et al. $2015,85 \%$ and $75 \%$, respectively), with the exception of a population in the southern Cascade Range in Oregon (Aubry and Raley 2006, 55\% and 40\%, respectively). Genetic analysis of the southern Cascades population indicated that fishers in the study were descended from individuals translocated to the area from British Columbia and Minnesota between 1977 and 1981 (Aubry and Raley 2006), which may at least partially explain observed differences in reproductive parameters.

We quantified the difference between attempted and successful reproduction where data were available because this distinction may improve accuracy of demographic models. In areas where an appreciable portion of den attempts are unsuccessful, future research could focus on identifying causes of den failure and facilitating strategies to increase success. Understanding why females of breeding age might not give birth at a given opportunity also can provide insights into constraints on reproductive success. In our study area, females that were old enough to reproduce but did not exhibit signs of denning weighed less than those that initiated dens. This suggests that body condition may have a physiological influence on a female's capacity to give birth, as has been documented for other species (Robbins et al. 2012). Other explanations for females skipping den opportunities include unsuccessful mating or energetic costs negatively affecting survival (especially for younger females-Woodroffe and Macdonald 1995; Nilsen et al. 2010). Identifying factors affecting reproduction that could be addressed by managers (e.g., access to high-quality foraging habitat) would be valuable for conservation plans.

Litter size.-Relatively few sources provided data on litter size in fishers, especially in wild settings; additionally, sources were not distributed evenly across the range, and available data included both captive and wild fishers. From these data, however, fishers appear to have relatively smaller litter sizes than some generalist carnivores like striped skunks (Mephitis mephitis-Wade-Smith and Verts 1982) or coyotes (Canis latrans-Sacks 2005), but litter sizes are comparable to those for more closely related species such as martens or wolverines (Mead 1994). Although data on litter size for species within the Martes Complex (Proulx and Aubry 2014) are limited, available information indicates that the range-wide mean litter size for fishers (2.5) is slightly below values for the smaller-bodied pine marten (Martes martes, mean 2.8, range: 1-5-Wijsman 2012) and American marten (M. americana, mean 2.9, range: 1-4-Erb et al. 2013), but just above values for the largerbodied wolverine (mean 1.9-2.0, range: 1-4-Magoun and Copeland 1998; Persson et al. 2006). We also found a linear relationship between litter size and latitude in western North America (where data were available), with the lowest mean litter sizes from the SSN (1.57 in this study; 1.6 from Sweitzer et al. 2015). Estimates of litter size within the West Coast DPS were similar to those in the rest of the range in that all values were below 2.0 (except for 1 study with a small sample size).

Estimates of litter size based on counts of corpora lutea and blastocysts tended to overestimate the number of kits born, whereas counts of placental scars (Crowley et al. 1990) were comparable to values from den monitoring. Counts of kits best reflect the number of live young produced per female, although early counts may overestimate kit survival to later stages and counts late in the den season may underestimate the number born. In our review and field study, we estimated litter size from numbers of kits known to be produced without subtracting losses due to mortalities. However, reductions in litter size (partial loss) are important to document because they influence overall productivity and further exacerbate small litter sizes. Loss or abandonment of individual kits appears to be infrequent for fishers, but has been documented in captive and 


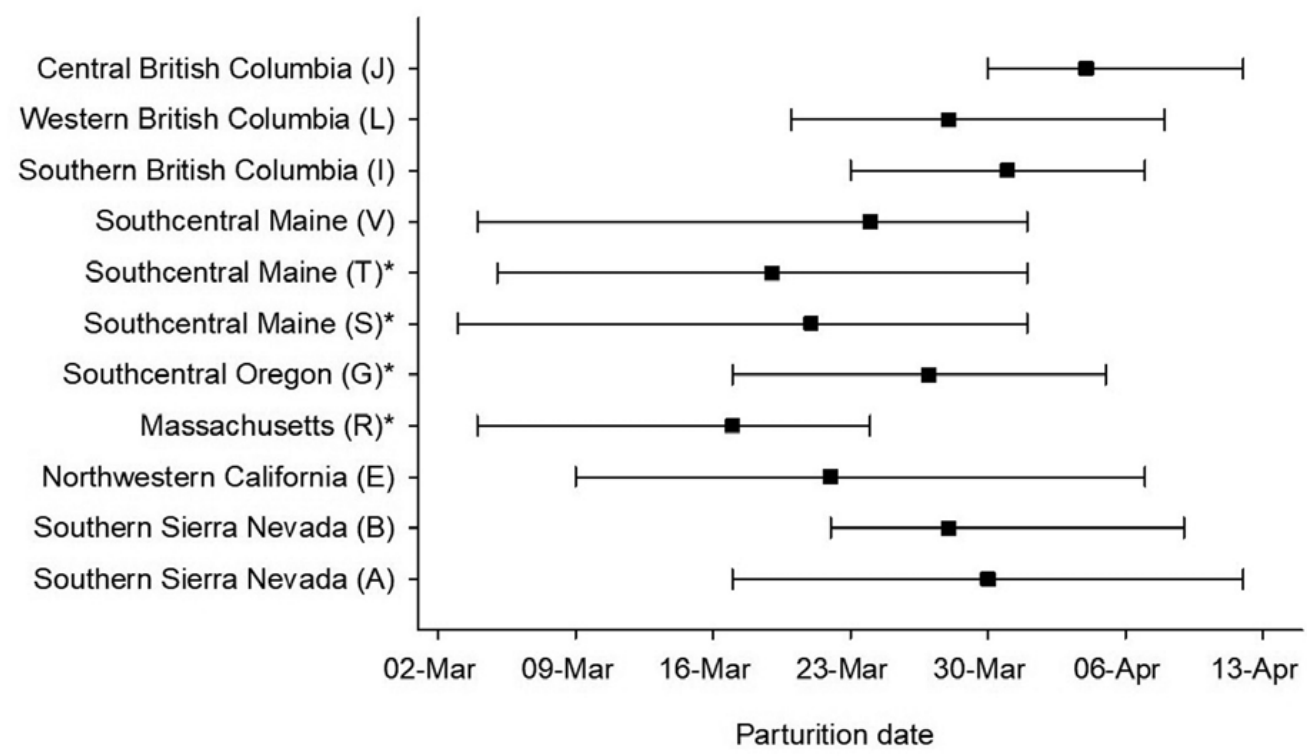

Fig. 5.-Mean or median (denoted by asterisks) parturition dates from 11 studies across the range of fisher (Pekania pennanti) in North America, including both wild (9) and captive settings (2). Study sites are arranged from north (top) to south (bottom) and letters indicate source materials referenced in Table 2 and Fig. 3. Horizontal bars represent the range of dates reported by these authors.

Table 4.- - Results of fisher (Pekania pennanti) den monitoring on the Kings River Fisher Project (2008-2014). Across 7 den seasons, 35 individual females reproduced in $\geq 1$ year. $S D$ was generated from annual data and represents some degree of annual variation.

\begin{tabular}{|c|c|c|c|c|c|c|c|c|c|}
\hline Metric associated with fisher reproduction & 2008 & 2009 & 2010 & 2011 & 2012 & 2013 & 2014 & Total & Mean $( \pm S D)$ \\
\hline Den opportunities & 7 & 16 & 15 & 11 & 14 & 20 & 10 & 93 & $13.3( \pm 4.3)$ \\
\hline Den attempts & 7 & 14 & 13 & 9 & 11 & 18 & 8 & 80 & $11.4( \pm 3.9)$ \\
\hline Den successes & 5 & 11 & 12 & 7 & 9 & 16 & 8 & 68 & $9.70( \pm 3.6)$ \\
\hline Den failure due to female mortality & 0 & 1 & 1 & 0 & 0 & 1 & 0 & 3 & $0.40( \pm 0.5)$ \\
\hline Unknown fate of den attempts due to collar loss & 2 & 0 & 0 & 0 & 0 & 0 & 0 & 2 & $0.30( \pm 0.8)$ \\
\hline Parturition date (mean) & $4 / 8$ & $3 / 27$ & $4 / 3$ & $4 / 3$ & $3 / 30$ & $3 / 29$ & $3 / 25$ & & $3 / 30$ \\
\hline Parturition date ( $\pm S D$ in days) & \pm 5 & \pm 3 & \pm 5 & \pm 6 & \pm 5 & \pm 4 & \pm 6 & & \pm 5 \\
\hline Fisher kits counted & 10 & 18 & 22 & 19 & 12 & 26 & 11 & 118 & \\
\hline Litters counted & 7 & 12 & 13 & 10 & 9 & 17 & 7 & 75 & \\
\hline Litter size produced (mean value) & 1.43 & 1.50 & 1.69 & 1.90 & 1.33 & 1.53 & 1.57 & & $1.57( \pm 0.2)$ \\
\hline
\end{tabular}

wild settings (York 1996; Frost and Krohn 1997; Matthews et al. 2013a).

Our results indicate that fishers tend to have larger litters in areas with greater seasonality or variability in temperatures (often at higher latitudes), and smaller litters in areas with warmer mean temperatures and greater mean precipitation (Fig. 5). These observations agree with Tökölyi et al. (2014), who suggested that in areas with harsh winters, larger litters may be a way to compensate for high winter mortality; the complement to this hypothesis would be a higher survival rate of young in areas with milder winters. At the southern margin of their range in the SSN, however, fishers may already be near their thermal tolerance limits, and the extent to which increased overwinter survival of young may be matched or exceeded by increased summer mortality is not clear. Climate models for the Sierra Nevada predict earlier snowmelt and drier late summer or fall conditions (Rauscher et al. 2008; Ashfaq et al. 2013). Fishers may have some ability to cope with warmer temperatures through behavioral adaptation (e.g., selection of cool microsites for resting), but persistently dry conditions during hotter summer months in the SSN could counter any increase in offspring survival during relatively milder winters. Another possibility is that litters with multiple kits may have an increased chance of surviving the early denning period in regions with colder temperatures because kits can share body warmth when the female is not present.

Alternative explanations for small litter size in the SSN relative to the rest of the range include diet limitations, smaller body size, and lower genetic diversity. The fisher diet in the SSN differs notably from that in other geographic areas. Although snowshoe hares (Lepus americanus) and porcupines (Erethizon dorsatum) are important prey items in much of the 
fisher's range (Martin 1994), they are largely unavailable in the SSN (Zielinski and Duncan 2004); instead, fishers subsist on a diverse array of relatively small food items, including squirrels, birds, carrion, fruit, lizards, and insects (Zielinski et al. 1999; Zielinski and Duncan 2004). The mean weight of adult female fishers in our study area $(\bar{X}=2.17 \mathrm{~kg}, S D \pm 0.19)$ was lower than reported for females further north (Maine, $\bar{X}=2.3 \mathrm{~kg}$ Frost et al. 1997; British Columbia, $\bar{X}=2.7 \mathrm{~kg}$-Weir and Corbould 2008). The extent to which this smaller body size is locally adaptive or reflects a broader geographic pattern (e.g., Bergmann's rule) remains unclear (Lofroth et al. 2010). Fisher populations in the SSN also have undergone long-term genetic isolation (Knaus et al. 2011; Tucker et al. 2012) and experienced genetic bottlenecks (Tucker et al. 2012). Recent studies have shown that fishers in this region exhibit extremely low genetic diversity in nuclear and mtDNA (Wisely et al. 2004; Knaus et al. 2011; Tucker et al. 2014). Whether reduced genetic diversity has affected fisher reproduction in this region is unknown, but inbreeding depression can be a concern in small or isolated populations (Lacy 1997).

Parturition dates.-Contrary to our prediction, parturition did not occur earlier at lower latitudes; instead, populations at middle latitudes (northern California, southern Oregon, Maine) generally had earlier parturition dates than those further north (British Columbia) or south (Sierra Nevada). Moreover, fishers in our study area gave birth later than the range-wide mean (30 versus 25 March), not earlier. The range of mean parturition dates from available sources across North America was rather narrow (12 March-8 April), and did not differ greatly from the full range of dates observed in the KRFP (17 March-12 April). However, parturition dates in the SSN tended to be later than other sites in the West Coast DPS.

Increased light exposure is believed to be the primary trigger for blastocyst implantation. In late January and February when implantation occurs, fishers at southern locations experience longer day length; but as day length increases after the winter solstice (21 December), changes in day length are greater and more rapid at more northern sites. The limited variation in parturition dates across nearly $19^{\circ}$ of latitude implies other factors may also influence this event (Mead 1989). For example, the apparent curvilinear relationship between parturition date and latitude may be explained by fishers giving birth at slightly later dates to increase likelihood of kit survival in areas that tend to have harsher late winter conditions (northern sites and southern sites at higher elevations). For example, historically, sites at low elevations in middle latitudes of northwestern coastal California may have experienced milder conditions in March and early April (e.g., warmer temperatures, less snow) than sites at higher elevations in the mountains of the SSN. Slightly later parturition dates in the SSN might limit the amount of time kits are exposed to cold temperatures while they are small and vulnerable. Prey availability may also influence parturition date; the pine marten (M. martes) has been recorded giving birth about a week later in years with low prey abundance (Kleef and Wijsman 2015). Body condition has been linked to timing of reproduction in European badgers (Meles meles), with females in better condition apparently able to finetune timing of parturition to maximize reproductive success (Woodroffe 1995). Powell et al. (2003) also noted that some female fishers gave birth around the same date each year, suggesting individual patterns may contribute to overall variation. Additional data from other geographic areas could help evaluate the potential influences of multiple factors on the timing of parturition, and the plasticity of parturition dates within individuals and populations.

Integration of reproductive parameters.-Although we focused on summarizing data for reproductive parameters separately in our review and field study, these parameters are likely integrated. At the level of the individual fisher, integration may involve trade-offs that are influenced by factors that vary geographically, such as type and abundance of prey, fisher density, habitat quality, or climatic conditions (e.g., harsh versus mild winters potentially affecting juvenile survival). For example, smaller litter size in the SSN appears to be associated with a relatively higher proportion of females reproducing; this pattern may indicate that the best strategy for females to maximize reproductive success over a lifetime in this region is to reproduce at most opportunities (i.e., each year), but have fewer kits per litter. Also, while parturition dates may be largely influenced by photoperiod, the variation in dates across the range could indicate regional adaptations that maximize kit survival, facilitate successful mating opportunities, or provide energetic benefits to individual denning females.

Fisher reproduction and conservation implications for the SSN.-Grinnell et al. (1937) was one of the first to suggest that a relatively low reproductive rate may limit fisher population growth; this assertion was supported by Hall (1942), who provided some of the 1st published records of fisher reproductive parameters. Fisher reproductive parameters in the SSN are similar to those in other geographic areas, but with notable local differences. In our study area, total reproductive output may be comparable to other geographic areas if small litter size is offset by a relatively high proportion of females reproducing; however, the tendency for females to have only 1 or 2 kits per litter means that survival of those kits to independence and adulthood may be especially important to sustain or grow the population. The baseline data on reproductive output for wild fishers in the SSN provided by this study can support development of local demographic models and life table analyses. However, future research efforts are needed to improve model accuracy by quantifying survival of different sex and age classes (including the proportion of kits that survive to independence) and identify whether reproductive output varies by age class for females. Finally, linking data on reproductive output to habitat in the SSN could help land managers identify and conserve forest types that may yield levels of output able to sustain fisher populations over time.

Another means of supporting fisher reproduction in managed landscapes is to reduce disturbance during sensitive periods (i.e., avoiding potentially disruptive management activities during specific dates). Parturition dates and the 
timeline of reproductive activities documented in this study can provide guidance on key time periods associated with reproduction for the SSN (Supplementary Data SD4); similar information could be compiled for other geographic areas. Disturbances (e.g., timber harvest, mechanical activities, prescribed fire) that occur between mid-March and late April seem likely to have the most significant negative impacts on fisher reproductive success as this is when natal den selection and parturition occur, followed closely by mating. Kits may also be at their most vulnerable during this time period due to the combination of small body size and cold ambient temperatures (Green 2017). Management activities that prevent females from getting back to their young or inhibit females from leaving the den to forage during warmer daytime temperatures have the potential to negatively impact kit survival. In May and early June, kits are physically larger and presumably more robust, but energetic demands on the females are higher as they need to produce more milk to feed larger kits while still meeting their own daily caloric needs (Powell and Leonard 1983; Bronson 1985); thus, disturbances to their foraging routine could have an impact. Photos from remote cameras and anecdotal observations at KRFP suggest that kits become increasingly difficult for the female to transport as they increase in size, potentially increasing risk of predation for the female and the kit during moves between den structures. Hence, disturbances in May, June, and even early July when kits are large but lack the mobility of an adult, could affect successful reproduction. The level of impact of an activity during the fisher den season may thus vary by both the type and timing of disturbance, as noted by Thompson and Purcell (2016) in relation to disproportionate risks associated with prescribed fire for neonatal fisher kits.

Prior to our study and a complementary field study farther north in this region (Sweitzer et al. 2015), data on fisher reproduction in the SSN were scarce. Both studies indicate potential limitations on reproductive output (specifically litter size) by fishers at the southern extent of their range in North America. Environmental conditions for fishers living in this southernmost region differ from those at higher latitudes, which may in turn influence their reproductive strategies and outcomes. Historically, conditions in the SSN may have favored a high proportion of females reproducing, small litters, and slightly later parturition dates because these parameters maximize reproductive success in this region. However, forest conditions in the SSN have changed over the last century; the most recent (2015-2017) modification is extensive tree mortality related to drought and bark beetles, with changes projected by climate models (Cayan et al. 2008; Priesler et al. 2017; Crockett and Westerling 2018). As the reproductive strategy for fishers in this region may depend on a relatively high success rate for denning females $(\sim 75 \%)$ paired with at least a moderately high rate of juvenile survival (based on small litter size), future monitoring of these parameters may be needed to evaluate the status of fisher populations in this region as they respond to new habitat conditions.

\section{ACKNOWLeDgMents}

Sincere thanks to the many field technicians that contributed to this research, including J. Banaszak, T. Brickley, S. Brink, J. Garner, N. Hebert, C. Indelicato, C. Larsen, J. Latter, M. Linnell, G. Merrill, Z. Miller, B. Nichols, A. Reyes, S. Rossler, J. Schneiderman, T. Smith, Z. Stoll, L. VanVranken, and G. Watts. We thank R. Sweitzer and the Sierra Nevada Adaptive Management Project fisher crew for aerial telemetry assistance. Financial and logistical support was provided largely by the USDA Forest Service, Region 5. REG recognizes financial support from the American Society of Mammalogists (Grants-in-Aid of Research) and 2 student grants through the University of California, Davis (Jastro-Shields Award, Walter and Elizabeth Howard Wildlife Management Award). We thank Southern California Edison for land access. We thank S. Matthews, M. Higley, and Hoopa Tribal Forestry for developing an exceptional fisher den monitoring program on which to model aspects of our research. We are grateful to W. Zielinski and A. Facka for comments on terminology and J. Baldwin for statistical advice. We appreciate W. Zielinski and 2 anonymous reviewers for editorial comments that greatly improved this manuscript. And we thank the following for allowing us to cite data on fisher reproduction: K. Aubry and C. Raley (Oregon), R. Callus and C. James (California), D. Clayton (Oregon), J. Erb (Minnesota), M. Higley and S. Matthews (California), L. Simpson of Keystone Wildlife Research (British Columbia), R. Truex (California), and R. Weir (British Columbia).

\section{SupPlementary Data}

Supplementary data are available at Journal of Mammalogy online.

Supplementary Data SD1.-Spreadsheet containing a summary of source material on fisher (Pekania pennanti) reproduction from our literature review.

Supplementary Data SD2.- Table showing results of the first 2 principal component axes based on climate variables from sites with data on 3 fisher (Pekania pennanti) reproductive parameters.

Supplementary Data SD3.-Figure showing weights of female fishers (Pekania pennanti) relative to denning status.

Supplementary Data SD4.-Timeline of fisher (Pekania pennanti) reproduction in the southern Sierra Nevada.

\section{Literature Cited}

Allen-Diaz, B., R. Standiford, and R. D. Jackson. 2007. Oak woodlands and forests. Pp. 313-338 in Terrestrial vegetation of California (M. G. Barbour, T. Keeler-Wolf, and A. A. Schoenherr, eds.). 3rd ed. University of California Press, Berkeley.

ArthuR, S., AND W. KRoHn. 1991. Activity patterns, movements, and reproductive ecology of fishers in southcentral Maine. Journal of Mammalogy 72:379-385.

AshfaQ, M., ET AL. 2013. Near-term acceleration of hydroclimatic change in the western U. S. Journal of Geophysical Research: Atmospheres 118:10676-10693. 
Aubry, K. B., And D. B. Houston. 1992. Distribution and status of the fisher (Martes pennanti) in Washington. Northwestern Naturalist 73:69-79.

Aubry, K. B., AND J. C. LewIs. 2003. Extirpation and reintroduction of fishers (Martes pennanti) in Oregon: implications for their conservation in the Pacific states. Biological Conservation 114:79-90.

Aubry, K. B., K. S. McKelvey, and J. P. Copeland. 2007. Distribution and broadscale habitat relations of the wolverine in the contiguous United States. Journal of Wildlife Management 71:2158-2147.

Aubry, K. B., And C. M. Raley. 2006. Ecological characteristics of fishers (Martes pennanti) in the southern Oregon Cascade Range. USDA Forest Service, Pacific Northwest Research Station, Olympia Forestry Sciences Laboratory. Update, Olympia, Washington.

Aubry-Kientz, M., and E. V. Moran. 2017. Climate impacts on tree growth in the Sierra Nevada. Forests 8:414-432.

BARDING, E. E., AND M. J. LACKI. 2014. Demographic and reproductive characteristics of reintroduced northern river otters in Kentucky: implications for population growth. American Midland Naturalist 172:338-347.

Bronson, F. H. 1985. Mammalian reproduction: an ecological perspective. Biology of Reproduction 32:1-26.

Brown, J. H., AND R. C. LAsiewski. 1972. Metabolism of weasels: the cost of being long and thin. Ecology 53:939-943.

Bywater, K. A., M. Apollonio, N. CAppai, and P. A. Stephens. 2010. Litter size and latitude in a large mammal: the wild boar Sus scrofa. Mammal Review 40:212-220.

California Department of Fish and Wildlife. 2015. Report to the Fish and Game Commission: a status review of the fisher (Pekania [formerly Martes] pennanti) in California. State of California, Natural Resources Agency, Department of Fish and Wildlife, Sacramento, California.

Cayan, D. R., E. P. Maurer, M. D. Dettinger, M. Tyree, and K. Haynoe. 2008. Climate change scenarios for the California region. Climatic Change 87:S21-S42.

Cherepak, R. B. 1993. Reproductive physiology of captive female and male fishers (Martes pennanti). M.S. thesis, University of Manitoba, Winnipeg, Manitoba, Canada.

Cherepak, R. B., And M. L. Connor. 1992. Constantly pregnant... well almost. Reproductive hormone levels of the fisher (Martes pennanti), a delayed implanter. Norwegian Journal of Agricultural Sciences Supplement 9:150-154.

Coulter, M. W. 1966. The ecology and management of fishers in Maine. Ph.D. dissertation, State University College of Forestry, Syracuse University, Syracuse, New York.

Crockett, J. L., And A. L. Westerling. 2018. Greater temperature and precipitation extremes intensify Western US droughts, wildfire severity, and Sierra Nevada tree mortality. Journal of Climate $1: 341-354$

Crowley, S. K., W. B. Krohn, and T. F. Paragi. 1990. A comparison of fisher reproductive estimates. Transactions of the Northeastern Section of the Wildlife Society 47:36-42.

Dixon, J. S. 1925. A closed season needed for fisher, marten, and wolverine. California Fish and Game 11:23-25.

Douglas, W. O. 1943. Fisher farming has arrived. American Fur Breeder 16:18-20.

Douglas, C. W., and M. A. Strickland. 1987. Fisher. Pp. 511-529 in Wild furbearer management and conservation in North America (M. Novak, J. A. Baker, M. E. Obbard, and B. Malloch, eds.). Ontario Ministry of Natural Resources, Toronto, Ontario, Canada.

ERB, J., P. CoY, AND B. SAmpson. 2013. Reproductive ecology of fishers and American martens in Minnesota. Pp. 100-109 in Summaries of wildlife research findings 2013 (L. Cornicelli, M. Carstensen,
M. D. Grund, M. A. Larson, and J. S. Lawrence, eds.). Minnesota Department of Natural Resources, St. Paul.

Facka, A. N., J. C. Lewis, P. Happe, K. Jenkins, R. Callas, and R. A. Powell. 2016. Timing of translocation influences birth rate and population dynamics in a forest carnivore. Ecosphere 7:e01223.

FAHRIG, L. 1997. Effects of habitat loss and fragmentation on population extinction. Journal of Wildlife Management 61:603-610.

Fites-Kaufman, J., P. Rundel, N. Stephenson, and D. A. Weixelman. 2007. Montane and subalpine vegetation of the Sierra Nevada and Cascade Ranges. Pp. 456-501 in Terrestrial vegetation of California (M. G. Barbour, T. Keeler-Wolf, and A. A. Schoenherr, eds.). 3rd ed. University of California Press, Berkeley.

Frost, H. C., AND W. B. KRoHn. 1997. Factors affecting the reproductive success of captive female fishers. Pp. 100-109 in Martes: taxonomy, ecology, techniques and management (G. Proulx, H. N. Bryant, and P. M. Woodard, eds.). Provincial Museum of Alberta, Edmonton, Alberta, Canada.

Frost, H. C., W. B. Krohn, and C. R. Wallace. 1997. Age-specific reproductive characteristics in fishers. Journal of Mammalogy 78:598-612.

Fuller, T. K., And P. R. Sievert. 2001. Carnivore demography and the consequences of changes in prey availability. Pp. 163-178 in Carnivore conservation (J. L. Gittleman, S. M. Funk, D. W. MacDonald, and R. K. Wayne, eds.). Cambridge University Press, London, United Kingdom.

Gabriel, M. W., et AL. 2015. Patterns of natural and human-caused mortality factors of a rare forest carnivore, the fisher (Pekania pennanti) in California. PLoS One 10:e0140640.

Gibilisco, C. J. 1994. Distributional dynamics of modern Martes in North America. Pp. 59-71 in Martens, sables, and fishers: biology and conservation (S. W. Buskirk, A. S. Harestad, M. G. Raphael, and R. A. Powell, eds.). Cornell University Press, Ithaca, New York.

Gittleman, J. L., And P. H. Harvey. 1982. Carnivore home-range size, metabolic needs and ecology. Behavioral Ecology and Sociobiology 10:57-63.

GLĄDALSKI, M., ET AL. 2014. Extreme weather event in spring 2013 delayed breeding time of great tit and blue tit. International Journal of Biometeorology 58:2169-2173.

Graham, R. W., and M. A. Graham. 1994. Late quaternary distribution of Martes in North America. Pp. 26-58 in Martens, sables, and fishers: biology and conservation (S. W. Buskirk, A. S. Harestad, M. G. Raphael, and R. A. Powell, eds.). Cornell University Press, Ithaca, New York.

GREEN, R. E. 2017. Reproductive ecology of the fisher (Pekania pennanti) in the southern Sierra Nevada: an assessment of reproductive parameters and forest habitat used by denning females. Ph.D. dissertation, University of California, Davis.

Green, R. E., M. J. Joyce, S. M. Matthews, K. L. Purcell, J. M. Higley, and A. Zalewski. 2017. Guidelines and techniques for studying the reproductive ecology of wild fishers (Pekania pennanti), American martens (Martes americana), and other members of the Martes Complex. Pp. 313-358 in The Martes Complex in the 21st century: ecology and conservation (A. Zalewski, I. A. Wierzbowska, K. B. Aubry, J. D. S. Birks, D. T. O'Mahony, and G. Proulx, eds.). Mammal Research Institute, Polish Academy of Sciences, Bialowieza, Poland.

Grinnell, J., J. S. Dixon, And J. M. Linsdale. 1937. Fur-bearing mammals of California. University of California Press, Berkeley. Vol. 1.

HALl, E. R. 1942. Gestation period in the fisher with recommendations for the animal's protection in California. California Fish and Game 28:143-147. 
Hall, L. E., A. D. Chalfoun, E. Z. Beever, and A. E. Loosen. 2016. Microrefuges and the occurrence of thermal specialists: implications for wildlife persistence amidst changing temperatures. Climate Change Responses 3:8.

Hamilton, W. J., And A. H. Cook. 1955. The biology and management of the fisher in New York. New York Fish and Game Journal 2:13-35

Hernández, F., W. P. Kuvlesky, Jr., R. W. DeYoung, L. A. Brennan, AND S. A. GALL. 2006. Recovery of rare species: case study of the masked bobwhite. Journal of Wildlife Management 70:617-631.

Hijmans, R. J., S. E. Cameron, J. L. Parra, P. G. Jones, and A. Jarvis. 2005. Very high resolution interpolated climate surfaces for global land areas. International Journal of Climatology 25:1965-1978.

Hodgson, R. G. 1937. Fisher farming. Fur Trade Journal of Canada, Toronto, Ontario, Canada.

James, C. E., K. R. Rulon, and M. A. Reno. 2008. Fisher monitoring within two industrially managed forests of northern California. Progress report to California Department of Fish and Game. Sierra Pacific Industries, Redding, California.

Kanapaux, W., AND G. A. KiKer. 2013. Development and testing of an object-oriented model for adaptively managing human disturbance of least tern (Sternula antillarum) nesting habitat. Ecological Modelling 268:64-77.

Keeley, J. E., And F. W. Davis. 2007. Chaparral. Pp. 339-366 in Terrestrial vegetation of California (M. G. Barbour, T. KeelerWolf, and A. A. Schoenherr, eds.). 3rd ed. University of California Press, Berkeley.

Keith, L. B., O. J. Rongstad, and E. C. Meslow. 1966. Regional differences in reproductive traits of the snowshoe hare. Canadian Journal of Zoology 44:953-961.

KleEF, H. L., AND J. W. WiJsman. 2015. Mast, mice and pine marten (Martes martes): the pine marten's reproductive response to wood mouse (Apodemus sylvaticus) fluctuations in the Netherlands. Lutra 58:23-33.

Knaus, B. J., R. Cronn, A. Liston, K. Pilgrim, and M. K. Schwartz. 2011. Mitochondrial genome sequences illuminate maternal lineages of conservation concern in a rare carnivore. BMC Ecology $11: 10$.

LACY, R. C. 1997. Importance of genetic variation to the viability of mammalian populations. Journal of Mammalogy 78:320-335.

Lada, H., J. R. Thomson, S. C. Cunningham, and R. Mac Nally. 2013. Rainfall in prior breeding seasons influences population size of a small marsupial. Austral Ecology 38:581-591.

LAURENSON, M. K. 1995. Behavioral costs and constraints of lactation in free-living cheetahs. Animal Behavior 50:815-826.

Leahy, L., ET AL. 2016. Amplified predation after fire suppresses rodent populations in Australia's tropical savannas. Wildlife Research 42:705-716.

LEONARD, R. D. 1986. Aspects of reproduction in the fisher, Martes pennanti, in Manitoba. Canadian Field-Naturalist 100:32-44.

Lewis, J. C., R. A. Powell, AND W. J. Zielinski. 2012. Carnivore translocations and conservation: insights from population models and field data for fishers (Martes pennanti). PLoS One 7:e32726.

LeWIS, J. C., AND W. J. ZiELINSKI. 1996. Historical harvest and incidental capture of fishers in California. Northwest Science 70:291-297.

Lofroth, E. C., ET AL. 2010. Conservation of fishers (Martes pennanti) in south-central British Columbia, western Washington, western Oregon, and California-volume 1: conservation Assessment. USDI Bureau of Land Management, Denver, Colorado.

LoRD, R. D. 1960. Litter size and latitude in North American mammals. The American Midland Naturalist 64:488-499.
LuČAn, R. K., M. WeISER, AND V. HanÁK. 2013. Contrasting effects of climate change on the timing of reproduction and reproductive success of a temperate insectivorous bat. Journal of Zoology 290:151-159.

Magoun, A. J., And J. P. Copeland. 1998. Characteristics of wolverine reproductive den sites. Journal of Wildlife Management 62:1313-1320.

Mann, M. E., AND P. H. GLeICK. 2015. Climate change and California drought in the 21st century. Proceedings of the National Academy of Sciences of the United States of America 112:3858-3859.

Martin, S. K. 1994. Feeding ecology of American martens and fishers. Pp. 297-315 in Martens, sables, and fishers: biology and conservation (S. W. Buskirk, A. S. Harestad, M. G. Raphael, and R. A. Powell, eds.). Cornell University Press, Ithaca, New York.

Matthews, S. M., et AL. 2013a. Reproduction, recruitment, and dispersal of fishers (Martes pennanti) in a managed Douglas-fir forest in California. Journal of Mammalogy 94:100-108.

Matthews, S. M., ET AL. 2013b. An evaluation of a weaning index for wild fishers (Pekania [Martes] pennanti) in California. Journal of Mammalogy 94:1161-1168.

McCune, B., J. B. Grace, and D. L. Urban. 2002. Analysis of ecological communities. MjM Software Design, Gleneden Beach, Oregon.

McCune, B., AND M. J. MefFord. 2011. PC-ORD. Multivariate analysis of ecological data. Ver. 6. MjM Software, Gleneden Beach, Oregon.

Mead, R. A. 1989. The physiology and evolution of delayed implantation in carnivores. Pp. 437-464 in Carnivore behavior, ecology and evolution (J. L. Gittleman, ed.). Cornell University Press, Ithaca, New York.

Mead, R. A. 1994. Reproduction in Martes. Pp. 404-422 in Martens, sables, and fishers: biology and conservation (S. W. Buskirk, A. S. Harestad, M. G. Raphael, and R. A. Powell, eds.). Cornell University Press, Ithaca, New York.

Miller, C. S., M. Hebblewhite, Y. K. Petrunenko, L. V. Seryodkin, J. M. Goodrich, And D. G. Miquelle. 2014. Amur tiger (Panthera tigris altaica) energetic requirements: implications for conserving tigers. Biological Conservation 170:120-129.

Millspaugh, J., AND J. M. MarZluff. 2001. Radio tracking and animal populations. Academic Press, San Diego, California.

Nilsen, E. B., H. Brøseth, J. Odden, and J. D. Linnell. 2010. The cost of maturing early in a solitary carnivore. Oecologia 164:943-948.

Oftedal, O. T., and J. L. Gittleman. 1989. Patterns of energy output during reproduction in carnivores. Pp. 355-378 in Carnivore behavior, ecology and evolution (J. L. Gittleman, ed.). Cornell University Press, Ithaca, New York.

Paragi, T. F., S. M. Arthur, and W. B. Krohn. 1994. Seasonal and circadian activity patterns of female fishers, Martes pennanti, with kits. Canadian Field Naturalist 108:52-57.

Paragi, T. F., S. M. Arthur, And W. B. Krohn. 1996. Importance of tree cavities as natal dens for fishers. Northern Journal of Applied Forestry 13:79-83.

Pearson, O. P., AND R. K. Enders. 1943. Duration of pregnancy in certain mustelids. Journal of Experimental Zoology 95:21-35.

Persson, J., A. Landa, R. Andersen, and P. Segerstrom. 2006. Reproductive characteristics of female wolverines (Gulo gulo) in Scandinavia. Journal of Mammalogy 87:75-79.

Powell, R. A. 1977. Hunting behavior, ecological energetics and predator-prey community stability of the fisher (Martes pennanti). Ph.D. dissertation, University of Chicago, Chicago, Illinois.

Powell, R. A. 1993. The fisher. 2nd ed. University of Minnesota Press, Minneapolis.

Downloaded from https://academic.oup.com/jmammal/advance-article-abstract/doi/10.1093/jmammal/gyy040/4980718 
Powell, R. A., S. W. Buskirk, And W. J. Zielinski. 2003. Fisher and marten. Pp. 635-649 in Wild mammals of North America: biology, management, and conservation (G. A. Feldhamer, B. C. Thompson, and J. A. Chapman, eds.). Johns Hopkins University Press, Baltimore, Maryland.

Powell, R., and R. Leonard. 1983. Sexual dimorphism and energy expenditure for reproduction in female fisher Martes pennanti. Oikos 40:166-174.

Powell, S. M., E. C. York, J. J. Scanlon, and T. K. Fuller. 1997. Fisher maternal den sites in central New England. Pp. 265-278 in Martes: taxonomy, ecology, techniques, and management (G. Proulx, H. N. Bryant, and P. M. Woodard, eds.). Provincial Museum of Alberta, Edmonton, Alberta, Canada.

Priesler, H. K., N. E. Grulke, Z. Heath, and S. L. Smith. 2017. Analysis and out-year forecast of beetle, borer, and drought-induced tree mortality in California. Forest Ecology and Management 399:166-178.

Proulx, G., And K. B. Aubry. 2014. The "Martes Complex" - an opportunity to bring together marten, fisher, sable, wolverine, and tayra biologists. Canadian Wildlife Biology and Management 3:30-32.

Purcell, K. L., A. K. Mazzoni, S. R. Mori, and B. B. Boroski. 2009. Resting structures and resting habitat of fishers in the southern Sierra Nevada, California. Forest Ecology and Management 258:2696-2706.

R Core Development Team. 2015. R: a language and environment for statistical computing. R Foundation for Statistical Computing, Vienna, Austria. www.R-project.org/. Accessed 2017.

Rauscher, S. A., J. S. Pal, N. S. Diffenbaugh, and M. Bendedtti. 2008. Future changes in snowmelt-driven runoff timing over the western US. Geophysical Research Letters 35:L16703.

Robbins, C. T., M. Ben-David, J. K. Fortin, and O. L. Nelson. 2012. Maternal condition determines birth date and growth of newborn bear cubs. Journal of Mammalogy 93:540-546.

SACKs, B. N. 2005. Reproduction and body condition of California coyotes (Canis latrans). Journal of Mammalogy 86:1036-1041.

SADLEIR, R. M. F. S. 1969. The ecology of reproduction in wild and domestic mammals. Methuen and Co., Limited, London, United Kingdom.

ScheEle, B. C., ET AL. 2016. High adult mortality in disease-challenged frog populations increases vulnerability to drought. The Journal of Animal Ecology 85:1453-1460.

Scheller, R. M., W. D. Spencer, H. Rustigian-Romsos, A. D. Syphard, B. C. WARD, and J. R. Strittholt. 2011. Using stochastic simulation to evaluate competing risks of wildfires and fuels management on an isolated forest carnivore. Landscape Ecology 26:1491-1504.

Self, S., and R. Callas. 2006. Pacific fisher natal and maternal den study: progress report no. 1, January 9, 2006 to June 9, 2006. On file with the U. S. Fish and Wildlife Service, Yreka, California.

SEglund, A. E. 1995. The use of resting sites by the Pacific fisher. M.S. thesis, Humboldt State University, Arcata, California.

Shea, M. E., N. L. Rollins, R. T. Bowyer, and A. G. Clark. 1985. Corpora lutea number as related to fisher age and distribution in Maine. Journal of Wildlife Management 49:37-40.

Sikes, R. S., and The Animal Care and Use Committee of the American Society of Mammalogists. 2016. 2016 Guidelines of the American Society of Mammalogists for the use of wild mammals in research and education. Journal of Mammalogy 97:663-688.

SimpSON, K., ET AL. 2013. Part 7 Mammals. Terrestrial Vegetation and Wildlife Report. Site C Clean Energy Project. Report prepared for BC Hydro, Vancouver, British Columbia, Canada.
Spencer, W., H. Rustigian-Romsos, J. Strittholt, R. Scheller, W. Zielinski, AND R. TRUeX. 2011. Using occupancy and population models to assess habitat conservation opportunities for an isolated carnivore population. Biological Conservation 144:788-803.

StataCorP. 2011. Stata statistical software: release 12. StataCorp LP, College Station, Texas.

Sweitzer, R. A., V. D. Popescu, R. H. Barrett, K. L. Purcell, and C. M. Thompson. 2015. Reproduction, abundance, and population growth for a fisher (Pekania pennanti) population in the Sierra National Forest, California. Journal of Mammalogy 96:772-790.

TAPPER, S., AND J. Reynolds. 1996. The wild fur trade: historical and ecological perspectives. Pp. 28-44 in The exploitation of mammal populations: past, present and future (V. J. Taylor and N. Dunstone, eds.). Chapman and Hall, London, United Kingdom.

Thompson, C. M., R. E. Green, J. Sauder, K. L. Purcell, R. A. Sweitzer, And J. M. Arnemo. 2012. The use of radiotelemetry in research on Martes species: techniques and technologies. Pp. 284-319 in Biology and conservation of martens, sables, and fishers: a new synthesis (K. B. Aubry, W. J. Zielinski, M. G. Raphael, G. Proulx, and S.W. Buskirk, eds). Cornell University Press, Ithaca, New York.

Thompson, C. M., And K. L. Purcell. 2016. Conditions inside fisher dens during prescribed fires; what is the risk posed by spring underburns? Forest Ecology and Management 359:156-161.

TÖкÖlYI, J., J. Schmidt, And Z. BARTA. 2014. Climate and mammalian life histories. Biological Journal of the Linnean Society 111:719-736.

TomÁs, G. 2015. Hatching date vs laying date: what should we look at to study avian optimal timing of reproduction? Journal of Avian Biology 46:107-112.

Tucker, J. M., M. K. Schwartz, R. L. Truex, K. L. Pilgrim, and F. W. Allendorf. 2012. Historical and contemporary DNA indicate fisher decline and isolation occurred prior to the European settlement of California. PLoS One 7:e52803.

Tucker, J. M., M. K. Schwartz, R. L. Truex, S. M. Wisely, and F. W. Allendorf. 2014. Sampling affects the detection of genetic subdivision and conservation implications for fisher in the Sierra Nevada. Conservation Genetics 15:123-136.

United States Fish and Wildlife Service. 2014. Endangered and threatened wildlife and plants; threatened species west coast distinct population segment of fisher. Federal Register 79:60419-60443. https://federalregister.gov/a/2014-23456. Accessed 2017.

Wade-Smith, J., AND B. J. Verts. 1982. Mephitis mephitis. Mammalian Species 173:1-7.

Webber, A. F., J. A. Heath, and R. A. Fischer. 2013. Human disturbance and stage-specific habitat requirements influence snowy plover site occupancy during the breeding season. Ecology and Evolution 3:853-863.

WeIR, R. D. 2009. Fisher ecology in the Kiskatinaw Plateau Ecosystem. Year-end report. Artemis Wildlife Consultants, Armstrong, British Columbia, Canada.

Weir, R. D., And F. B. Corbould. 2008. Ecology of fishers in the sub-boreal forests of north-central British Columbia, final report. Peace/Williston Fish and Wildlife Compensation Program Report No. 315. Fish and Wildlife Compensation Program, Prince George, British Columbia, Canada.

Wengert, G. M., Et AL. 2014. Using DNA to describe and quantify interspecific killing of fishers in California. Journal of Wildlife Management 78:603-611. 
Wissman, H. J. W. 2012. The effects of small rodent density fluctuations on the pine marten (Martes martes). Lutra 55:29-40.

Wisely, S. M., S. W. Buskirk, G. A. Russell, K. B. Aubry, and W. J. ZIELINSKI. 2004. Genetic diversity and structure of the fisher (Martes pennanti) in a peninsular and peripheral metapopulation. Journal of Mammalogy 85:640-648.

Wittemyer, G., J. M. Northrup, J. Blanc, I. Douglas-Hamilton, P. OMOndi, AND K. P. BuRnham. 2014. Illegal killing for ivory drives global decline in African elephants. Proceedings of the National Academy of Sciences of the United States of America 36:13117-13121.

Woodroffe, R. 1995. Body condition affects implantation date in the European badger, Meles meles. Journal of Zoology 236:183-188.

Woodroffe, R., AND D. W. Macdonald. 1995. Costs of breeding status in the European badger, Meles meles. Journal of Zoology 235:237-245.

YoRK, E. 1996. Fisher population dynamics in north-central Massachusetts. M.S. thesis, University of Massachusetts, Amherst. Zielinski, W. J., J. A. Baldwin, R. L. Truex, J. M. Tucker, and P. A. FlebBe. 2013. Estimating trend in occupancy for the southern
Sierra Fisher Martes pennanti population. Journal of Fish and Wildlife Management 4:3-19.

ZiELINSKI, W. J., AND N. P. DunCan. 2004. Diets of sympatric populations of American martens (Martes americana) and fishers (Martes pennanti) in California. Journal of Mammalogy 85:470-477.

Zielinski, W. J., N. P. Duncan, E. C. Farmer, R. L. Truex, A. P. Clevenger, and R. H. Barrett. 1999. Diet of fishers (Martes pennanti) at the southernmost extent of their range. Journal of Mammalogy 80:961-971.

Zielinski, W. J., R. L. Truex, F. V. Schlexer, L. A. Campbell, and C. Carroll. 2005. Historical and contemporary distributions of carnivores in forests of the Sierra Nevada, California, USA. Journal of Biogeography 32:1385-1407.

Zielinski, W. J., R. L. Truex, G. A. Schmidt, F. V. Schlexer, K. N. Schmidt, AND R. H. BARRETt. 2004. Resting habitat selection by fishers in California. Journal of Wildlife Management 68:475-492.

Submitted 28 September 2017. Accepted 27 March 2018.

Associate Editor was Bill Zielinski. 